\title{
Analysis of Production System Management of Ghana's Food and Beverage Industry: Empirical evidence from Spare Parts Inventory Control, Production Quality and Maintenance Modeling
}

\author{
Daniel Owusu-Mensah \\ Mechanical Engineering Department, Jiangsu University, Zhenjiang, China \\ $\&$ \\ Faculty of Agriculture, Kwame Nkrumah University of Science and Technology, \\ Kumasi, Ghana \\ Professor Ren Naifei (Corresponding author) \\ Mechanical Engineering Department, Jiangsu University, Zhenjiang, China \\ E-mail: rnf_ujs@126.com
}

Brako Lydia

School of Medicine, Jiangnan University, Wuxi, China

Priscilla Boateng

School of Business, Hohai University, Nanjing, China

Williams Kweku Darkwah

Environmental Engineering Department, Hohai University, Nanjing, China

Received: February 22, 2020

doi:10.5296/jfi.v4i1.16511
Accepted: March 31, 2020 Published: April 13, 2020

URL: http://dx.doi.org/10.5296/jfi.v4i1.16511 


\section{Macrothink}

\section{Abstract}

The production systems of various industries have increasingly become a strategic business management function that drives differentiation and competitive edge. Production plant maintenance is therefore an integral part of an entire production system management function, which should encapsulate spare part inventory control systems, total quality assurance, improvement measures and cost control measures. This project sought to understand the production process of firms in Ghana's food and beverage industry, assess the spare part inventory management practices, production quality control practices and maintenance management strategies implemented in order to recommend a maintenance optimization modeling system towards ensuring an optimal operation cost and production quality. Using both the inductive and deductive research approaches, the research project was exploratory and explanatory in nature. Three major players in Ghana's food and beverage industry: GIHOC-DCL (Ghana Industrial Holding Corporation Distillery Limited), Heathy-Life Ghana Limited (Healthy-Life) and Parlays Ghana Limited (Parlays) were purposively sampled as industrial case studies to generate data from documentary secondary data and survey based sources. The functionality tools available in MATLAB/Simulink software assisted in formulating the maintenance optimization problem, modeling, analyzing and deriving solutions. The study found that the food and beverage processing business in Ghana has a positive correlation with the main agricultural produce of the country and involves a series of activities including processing and preservation of meat, fish, fruit, vegetables, starch products, bread and sugar. Spare part inventory management and quality control tools mainly applied include Statistical Control Charts and Check Sheet rather than optimization models and software.

Keywords: Food \& Beverage Industry, Production Systems, Maintenance Optimization, and Quality Control

\section{Introduction}

The production systems of various industries have increasingly become a strategic business management function that drives differentiation and competitive edge and thus, the propellers of growth in the world's economies. Accounting for about 5 percent of gross domestic product, 10 percent of total employment, 10 percent of US consumers' disposable personal income (DPI), total sales of $\$ 1.4$ trillion, nearly 27,000 establishments employing 1.46 million workers and also ensuring adequate, secure food supplies; food system sustainability; and nutritious diets (Committee for Economic Development (CED), 2017), the food and beverage industry revitalizes a buoyant US economy. Similarly, the textile, food and beverage, and iron and steel industries of Japan, Singapore, Indonesia, Malaysia, Taiwan and China for instance, are virtually the hub of production technology innovation and the medium for employment opportunities (Mwang'onda et al, 2018). Surely, manufacturing workforce skill development is imminent due to these production dynamics and complexity (Makhado and Sukdeo, 2018). To this end, companies in the manufacturing industry value effective and efficient management of their production plant operations in a manner that optimizes production cost, inventory use, production quality and profitability. Therefore, production 


\section{MInstitute ${ }^{\text {Macrothink }}$}

machinery efficiency is inextricably intertwined with the overall performance of a complete production system (Ma et al., 2018).

Production plant maintenance is an integral part of an entire production system management function that should encapsulate spare part inventory control systems, total quality assurance, improvement measures and cost control measures. According to Murthy et al. (2002), effective maintenance spans a multidisciplinary paradigm that involves technical and commercial issues, quantitative modeling and relevant systems information. An empirical study conducted at a weaving machine in a Slovenian textiles company confirmed that $3.22 \%$ of profit and a quality improvement rate of about $2 \%$ could be generated if all unplanned stoppages and loss of quality due to decrease in the productivity would be prevented (Maletic et al., 2012). However, maintenance management practices in the food and beverage industry gets convoluted mainly due to the dynamics of consumer behavior and market expansion trends. Plants are configured with a range of systems and components must work seamlessly together to provide quality production, reduce costs and time to market. The processes that transform raw inputs into final products are complex as a result of the myriad of biochemical reactions and matter transference between phases taking place in the primary processes (Marchal et al., 2018).

This therefore requires a holistic and comprehensive optimization modeling and analysis tools that embeds critical aspects of the entire process in order to achieve optimal cost and profit levels without compromising quality output. Marquez \& Gupta, (2006); Jiang and Murthy (2008) confirmed that building models using concepts and techniques from reliability theory, statistics and stochastic processes is as important as the understanding of different equipment failure mechanisms.

This research therefore sought to understand the production process of firms in Ghana's food and beverage industry, assess the spare part inventory management, production quality control and maintenance management strategies and models implemented, in order to design a maintenance optimization system model that considers critical production system parameters; spare part inventory, production quality and maintenance acts, towards ensuring an optimal operation cost and superior performance.

\section{Literature Review}

\subsection{Food and Beverage Industry Value Chain and Production System Processes}

The food and beverage industry has received great attention in the academic and business research community, with lots of studies emphasizing the core aspects of production processes that facilitate high productivity to ensure customer service satisfaction and product quality, but remains significantly silent of the key and critical aspects of maintenance optimization modeling and analysis. Existing literature have delved much into assessing global trends in the food and beverage industry as related to socio economic growth and virtually none on the production maintenance trends. In Europe, retailers' efficient supply chain management paved way for the food and drink industry sector. It is the greatest employer and economic value added activity, with about 4.2 million people employed, $1.8 \%$ 


\section{Macrothink}

of Europe's gross value and over 1.2 billion Euros turnover in 2015 (Zhong et al., 2017). Similarly, in Canada, the availability and low cost of raw materials, favorable exchange rates, low production cost and access to quality water were the major drivers of a buoyant food and beverage processing industry that gained $28 \%$ of all manufacturing revenues and $22 \%$ employment in the manufacturing sector (Ashton et al., 2014). The above results indicate consistency in production processes which is inherently made of efficient equipment maintenance. The food and agricultural organization of the United Nations (2018) analyzed the food and beverage industry trends in sub-Saharan Africa and found that with the increasing agro processing, the sector seemed to be stagnated. This was attributed to structural flaws of firms in the industry, which further connoted unstructured productions and maintenance systems.

\subsection{Critical Aspects of Food and Beverage Value Chain Processes}

Food processing is simply understood as the methods and techniques of transforming raw ingredients into food for human consumption, whiles a beverage is a drink consisting largely of water and prepared for human consumption (Nirr Project Consultancy Services Board, 2012). Three types of beverages: Raw beverages which require a higher degree of preparation, before being served to the customer. Tea, coffee and cocoa are examples. Semi-prepared beverages; which do not need to be prepared from the raw product state, but neither are they ready to serve and fully prepared beverages: which require virtually no preparation before being served to the customer, for example bottled fruit juices, spirits and wines (Politeknik NSC Surabaya, 2008).

The Natural Capital Coalition (2016) sums it up as all businesses operating in the sourcing and logistics, production, processing, or retailing, and recycling or reuse, of food and beverage products, excluding the hospitality services (Figure 1). These denote different tiers of production, and complex international trade supply chains. 


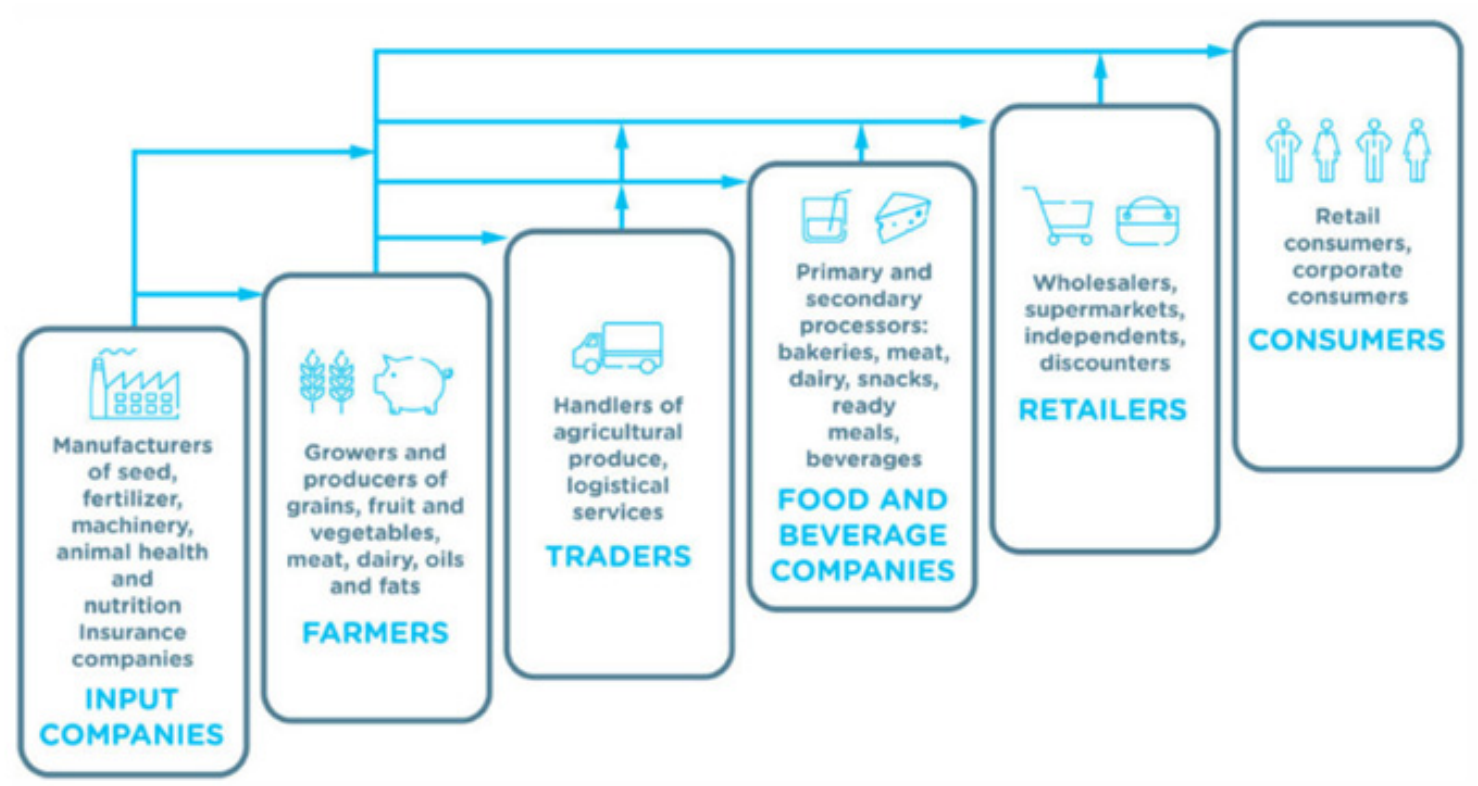

Source (NCC, 2016)

Figure 1. The Food and Beverage Value Chain

\subsection{Critical Aspects of Food and Beverage Industry Production Plant Processes}

A generic food and beverage firm production process covers a wide complex range of products being produced by varying size and location of processing plants and different manufacturing activities. It was explained that the processing method used depends on the type of materials to be removed and may include the use of water although dry methods conserves water and prevent wastage. Major steps in the fruit and vegetable production begins with the preparation of the raw food and beverages through a variety of methods including cleaning (removal and specification of organic and non-organic debris, metals, and pesticide), trimming and peeling to reduce the product to a uniform size before cooking, canning, drying or freezing, as well as pulping and filtration to make soft drinks. The process ends with packaging and transport of the final product (Figure 2). Examples of processed vegetable products are canned beans and frozen peas, and soft drink examples include beverage juices and concentrated fruit extracts for dilution with water (International Finance Cooperation (IFC), 2007). 


\section{MInstitute Macrothink}

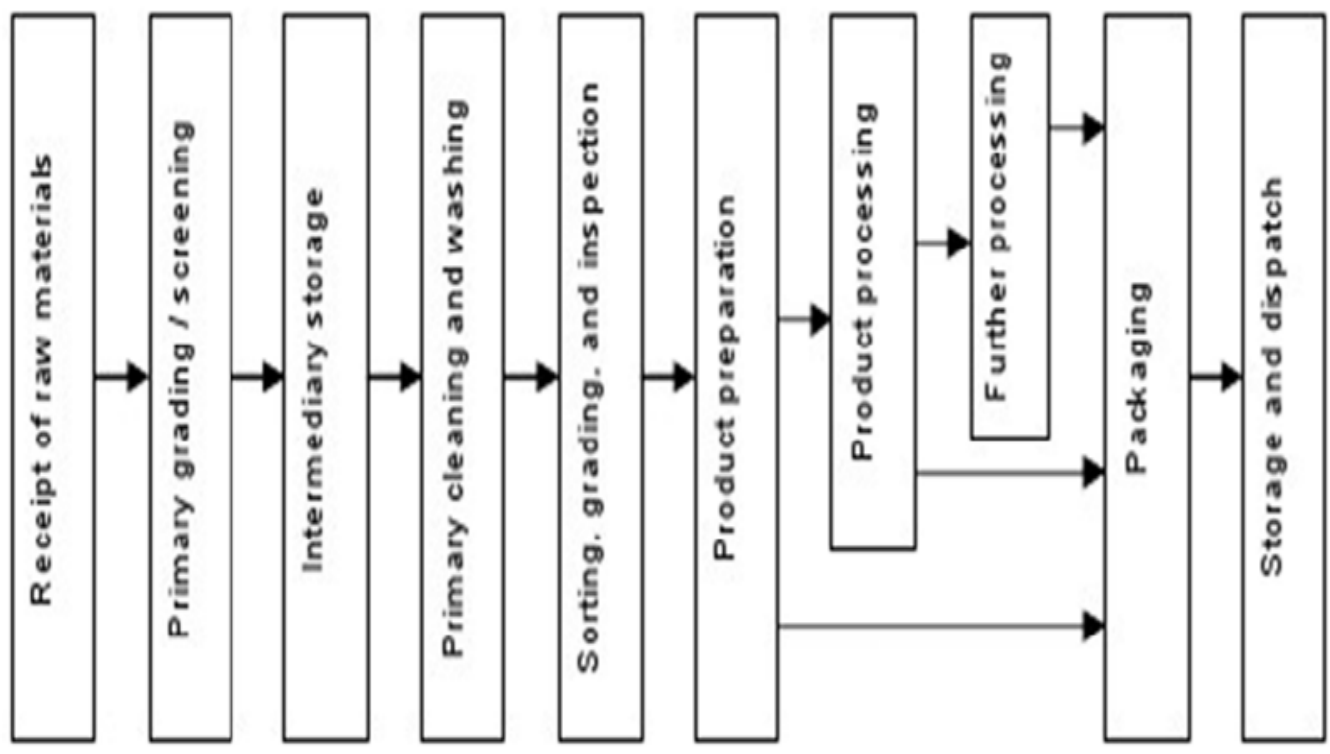

Source: (International Finance Cooperation (IFC), 2007).

Figure 2. General Process for Food and Beverage Production Operations

For food processing such as meat, received frozen, processing involves thawing after arrival to the processing plant using air, water showers, or water immersion techniques. They are then ground down and reconstituted into different product shapes using various processing machinery. Preservation techniques include heat, such as cooking (e.g. in water bath, shower, steam, and hot air ovens) and smoking, dehydration, fermentation, brining, curing, pickling; which are made of the injection of a saline solution, followed by a massaging process to ensure mixing of ingredients and product additives, and canning (International Finance Cooperation (IFC), 2007).

A core area of manufacturing system is the beverage packaging production line (BPPL) as espoused by Yan et al. (2008). The aspects of the BPPL plant are the bottle washer, packaging machine, pasteurizing machine, labeling machine, case-stack unloader, bottle-case separator, case washer, bottle-case uniter, and case-stack loader. The study identified the Virtual Manufacturing (VM) technology as a modeling and simulating tool that drives design quality and general efficiency in the production line.

Moreover, the efficient management of the food and beverage production process requires the control of five key areas; waste, overcooking, over portioning, improper carryover utilization and inappropriate make or buy decision, and applications of modern effective product storage and inventory technologies; including storage and maintenance of product security, maintenance of product inventory values by categories, maintain perpetual inventory, develop production schedules periodically according to sales forecast and compute LIFO or FIFO inventory values (Dopson \& Hages, 2015). 


\section{Macrothink}

Moreover, the Hazard Analysis and Critical Control Point (HACCP) is also important for successful food and beverage production, which involve the systematic identification and controlling of hazards, whether they are microbiological, chemical or physical in nature (Politeknik NSC Surabaya, 2008).

Finally, a general distinctive observation about the food and beverage industry production process is outlined by Marchal et al. (2018) as: the variability of input properties is rife and causes disturbances that affects process output and quality products, food products are complex in nature and difficult to measure online, and its multivariable processes cause disturbances

\subsection{Drivers of Competitive Advantage in the Food and Beverage Industry}

It is important to review literature on the crucial factors that makes the business management activities of firms in the food and beverage industry that influence their competitive operations. This is aimed at ascertaining the extent to which production plant maintenance plant operations are major drivers of competitive edge in the industry. A chunk of existing literature does not draw this relationship explicitly.

According to Infor (2012), food and beverage companies can only succeed if they deliver effective management of operational constraints made possible in part by an improved formulation strategy that ensures more value, faster, and for less cost. They there must ensure the following in order to remain competitive; deliver products with more nutritional value and fewer allergens, create more formula agility, continually drive down costs and minimize environment impact.

The UK food and beverage manufacturing industry for instance, combines eco-design, regulation compliance, clean production, product development and environmental sustainable strategies to achieve competitive advantage and expand market share (Nee et al., 2013). Additionally, Enzing (2009) conducted a competitive analysis of the Dutch food and beverage industry and revealed that companies that follow a prospector strategy, extensive market assessment and with high level of product innovation was successful and gained market leadership.

Other drivers of competitive edge in the European Union food and beverage industry are globalization and market power; migrant labour/movement of labour within the EU; retailers and the grocery market; regulation and compliance; consumer demands; technology and innovation and environmental change (Food \& Drink Research Network, 2013).

\subsection{Spare Part Inventory Control and Production Quality Assurance Strategies in the Food and Beverage Industry}

Existing literature on spare part inventory and production quality control systems have based on generic theories and models that explains these strategic contexts discretely. Only a few works have tried to analyze each of these systems in tandem with production maintenance policies. This research project therefore adds to existing knowledge by reviewing critical parameters and variables of spare part inventory and production quality as related to 


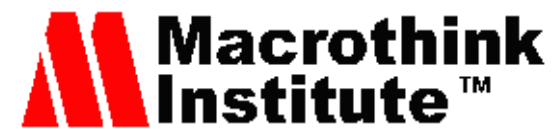

maintenance optimization modeling and analysis.

\subsubsection{Spare Parts Inventory Control Measures and Models}

A wide range of research works have proclaimed the vital role of inventory management in the food and beverage industry across global jurisdictions, especially because of its product perishability nature and total production cost (Nagib et al., 2016). Four main inventory models were proposed for the food and beverage industry; make-to-stock (MTS) policy, make-to-order (MTO) policy, economic order quantity (EOQ) and the hybrid of MTS-MTO inventory system (Figure 3. With the MTS policy products are produced and stored as determined by demand forecast. The MTO policy only produces as a result of demand from customers. A combination of the MTS and MTO in an organization forms the hybrid model system. Finally, the EOQ models assist inventory managers to decide how much inventory replenishment should be ordered and at what time should the order be placed.

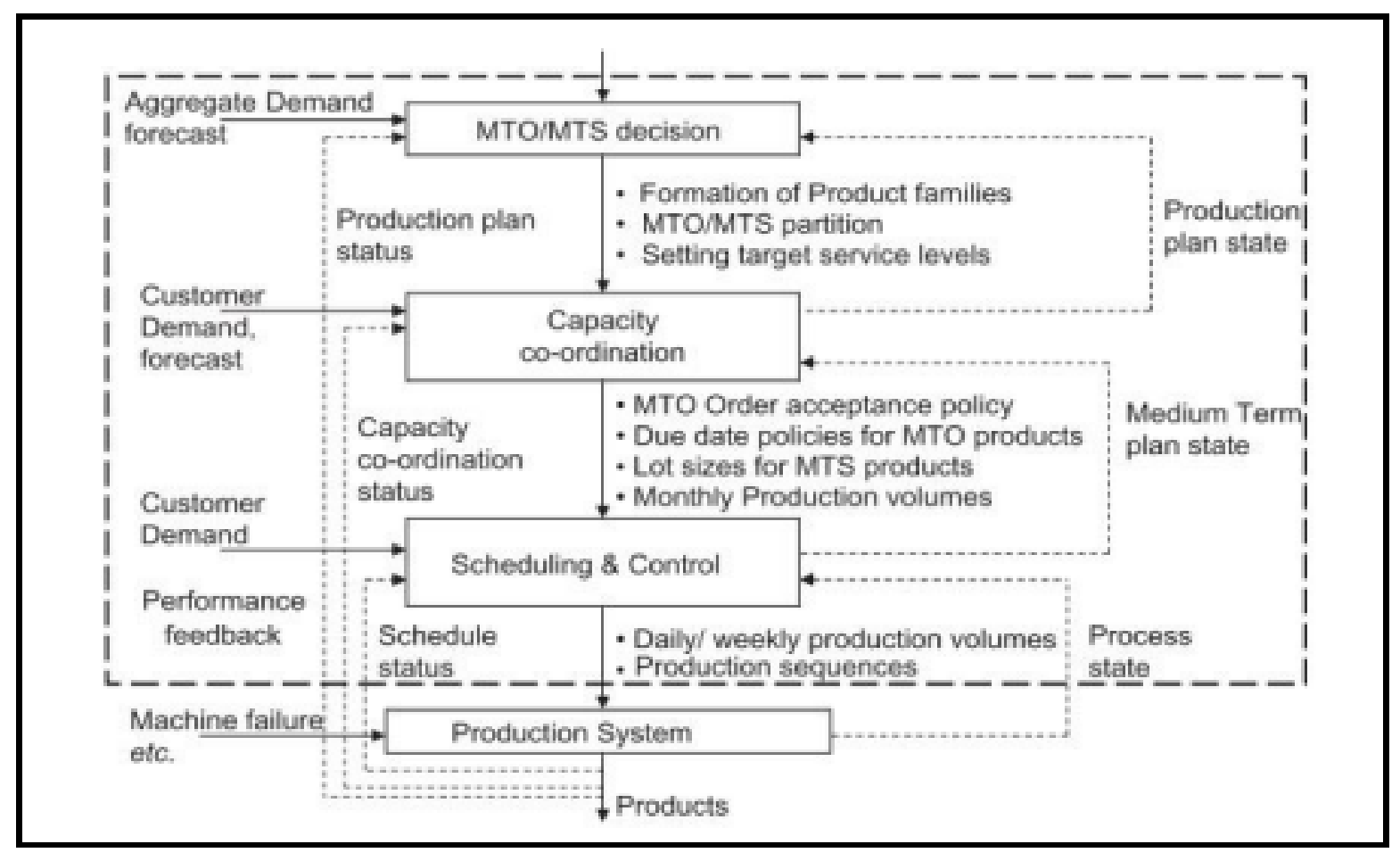

Figure 3. Hierarchical Approach to MTO-MTS Problem

Source: Nagib et al. (2016).

Al-Bawi (2015) discussed the essential asset of maintenance spare pare part management that is worth noting: ordering; it ensures allocation of ample time to make an order and the appropriate quantity of spare parts to order to ensure cost reduction. Parts storage; it puts into account parts that are stored securely and segregated for the right purposes. These are normally operated by computer systems for selection efficiency. Issuing; this aspects deals 


\section{$\triangle$ Macrothink}

with storing different types of parts to allow for easy access when needed. Controlling simply depicts the use of tools to provide information, including historical consumption, classification, and order point and quantity. Handling parts and supplies; it includes quality control and inspection to ensure correct inputting of spare parts quality, parts numbers, serial numbers, application, modifications, expiry date, and physical conditions (Al-Bawi, 2015). The influence of the timely availability of production equipment maintenance spare parts machines on production cost levels is also well appreciated by Kersten (2009), and thus the need to minimize such cost. Whiles it was admitted that spare part inventory machines lock up operating capital; the study advocated the need to improve on spare part inventory systems in order to minimize inventory holding cost and ramifications on overall logistics and supply chain profitability.

Notwithstanding the above, it was cautioned that receiving wrong parts are the most repeatable problem faced, where suppliers fail to supply the spare part specification given them (Al-Bawi, 2015). This may cause costly delays as the parts need to be returned and replaced. The supplier should therefore have the expertise of business operations of their client companies as expected.

An empirical study conducted by Gelagay and Balda (2018) on assessing the extent of inventory management practice in micro and small enterprises on the manufacturing industry in Arsi Zone, Ethiopia indicated an incapacity on firms to apply modern inventory management technologies, but are experts in judgment based forecasting (Figure 4).

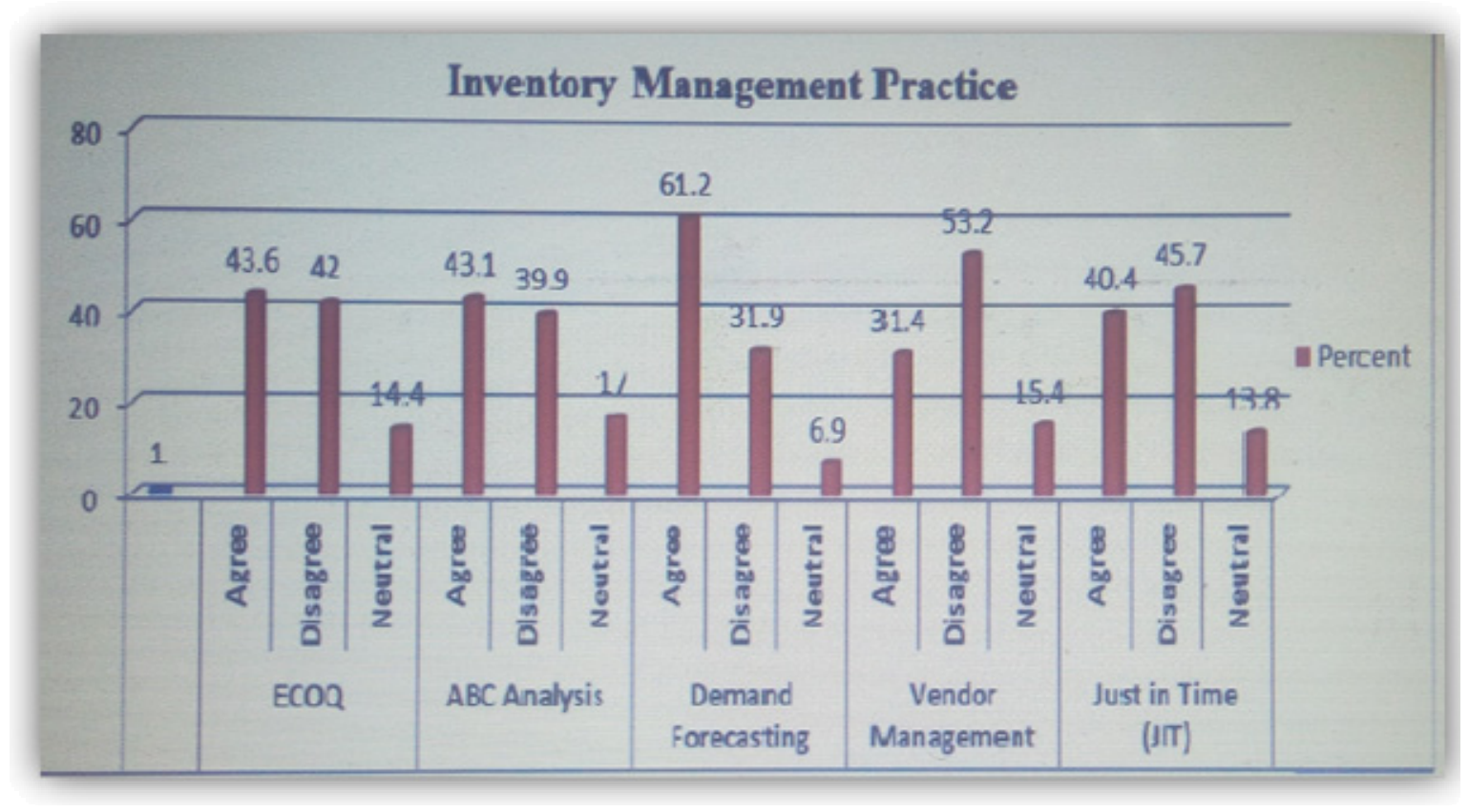

Figure 4. Inventory Management Practices in the Ethiopian Manufacturing Industry

Source: Gelagay and Balda (2018). 


\section{NInscrothink}

\subsubsection{Production Quality Control Measures and Models}

Brown (2014) defines Quality control (QC) and assurance as the act of ensuring that food and beverages meet the required quality standards at each processing step. QC was categorized under three broad methods; sampling schemes, analytical methods and statistical processes. Being sure that quality does not cost but pays instead, Hurst et al. (2010) developed a quality control program, that minimizes costly errors, and reduce the risk of food safety and defects. Basic quality control tools included in the program are: ingredient specifications, approved supplier list, product formulas, product standards specifications, manufacturing procedures, critical control point identification/sampling program, in-process analysis, records and reporting packaging specifications, label specifications, cleaning and sanitizing program, good manufacturing practices (GMP) requirements, recall program, warehousing, shipping and receiving program and laboratory analysis.

Moreover, although the complexities of food and beverage operation is unequivocal, Davis et al. (2013) proposed that customer quality can be delivered systematically using the Deming PDCA (Plan-Do-Check-Act) cycle (1982); This approach applies continual improvement methods to identify and correct production or service errors to ensure lasting quality improvement for customer requirements. The cycle stages include 'planning'; for clarification of the problem. The 'do' phase involves implementing small scale corrective experiments for 'checking' by measurement. Finally, 'act' means to implement the developed quality improvements measures.

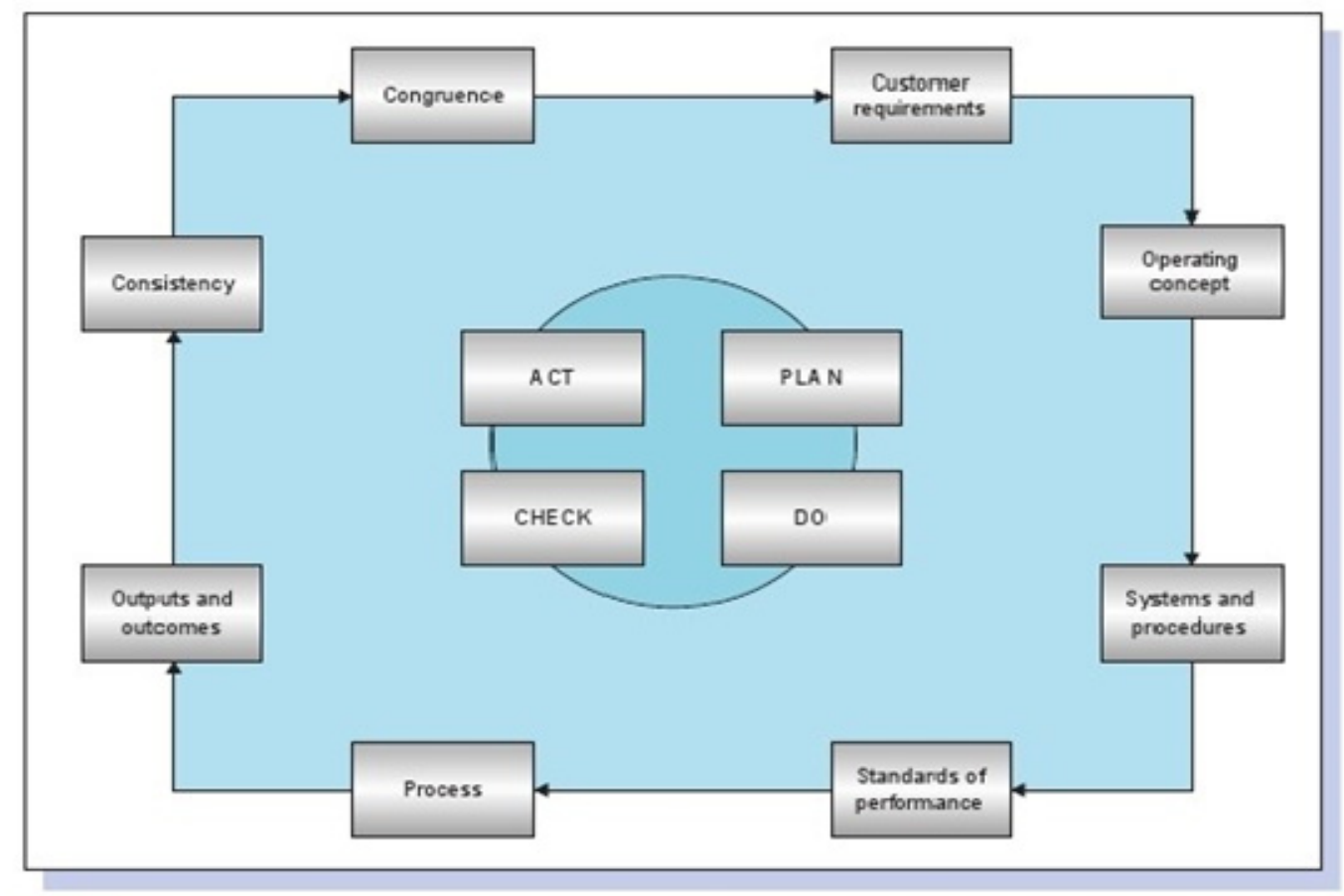

Source: Davis et al. (2013)

Figure 5. Plan-Do-Check-Act Quality Management Cycle 


\section{Mll Macrothink}

According to Davis et al. (2013), quality management approaches have evolved over time spanning from the quality inspection of the finished product; involving the checking for defects in a product or service before it reaches the customer, through quality control; which ensures detailed specification and checks made throughout the production process, and quality assurance; which avoid mistakes and ensures a design that identifies and correct errors as they happen, and finally to total quality management (TQM); which focus on achieving customer quality requirements at every stage of the value chain process .

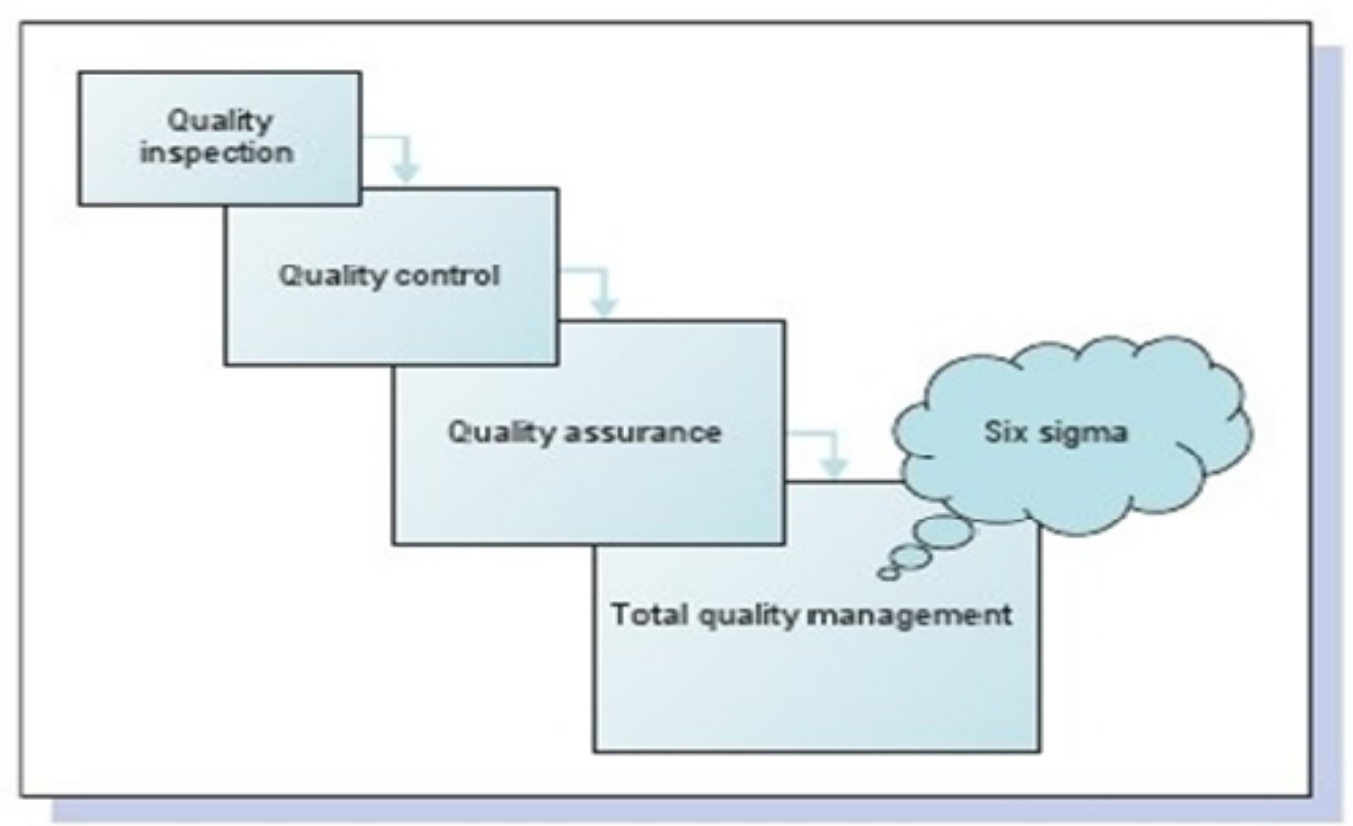

\section{Source: Davis et al. (2013)}

Figure 6. The Evolution of Production Quality Management Approaches

\subsection{Maintenance Management Challenges of the Food and Beverage Industry}

The global food and beverage industry is generally faced with some complex intertwined challenges that usually threatens the competitiveness of firms. (Ashayeri et al. (1995) identified and discussed the causes of some of these hurdles; it was explained that increased mechanization and automation require that a lot of maintenance has to be done. Thus, planning and systematized inspection can help avoid retaining large maintenance staffs for avoidable emergencies. Again, new production systems, like just-in-time production technology, with minimum stocks of finished products and work-in-process, have tremendous interruptions to production costly. Moreover, the frequent or intermittent shut down of plants for emergency maintenance, costs are even higher, given the fact that most in-process products are lost. This therefore leads to great strains on maintenance personnel and can lead to unsafe methods of operation and danger to the environment. To add to the above, it is also difficult to hire specialized maintenance personnel in case of an emergency. Determining the 
size of the maintenance crew is also another great challenge. Ultimately, the complexity of the maintenance models is dependent on whether single or multi-skilled craftsmen are present (Ashayeri et al., 1995).

Furthermore, Christiansen (2018) reviewed three of the most common maintenance challenges; multiple regulatory bodies, keeping highly automated and complex equipment running, and ensuring workers' safety, all while producing hygienic goods, being experienced in the food and beverage industry. The industry is highly regulated because its products are for human consumption. Firms cannot therefore compromise the strict control which may otherwise lead to contaminated products with the possibility of outbreaks, illnesses and lawsuits. First, maintaining complex and highly sensitive equipment of a typical food and drink processing plant today demands adept expertise and rapt attention. These assets; from peeling machines to refrigeration plants and packing machinery are part of a fast-moving production line that require specialized skills to monitor and keep in peak operating condition equipment are, every component demands constant attention. Consequently, operating these systems on reactive maintenance disproportionate interval alone where components are left to fail before repairs are carried out, will put the enterprise at the risk of shortening the lifespan of their assets (Christiansen, 2018).

Secondly, because the industry makes products for human consumption, food and beverage manufacturers must enforce hygienic practices and maintain their equipment under the highest standards of food safety. Failure to do this can lead to many serious problems like producing contaminated food, product recalls, foreign material complaints, lawsuits, outbreaks and infections (Christiansen, 2018).

Thirdly, manufacturers of edible products are subject to the regulations imposed by the relevant authorities in their various countries of operation. By implication, there is a wide range of regulation regarding food safety that firms in the food and beverage industry must deal with: ensure strict enforcement with policies and procedures that could vary from country to country. For example, manufacturers in the United States are subject to USDA Food Safety and Inspection Service (FSIS) regulations and those of the FDA. Food and drink processors in the UK are regulated by the Food Standards Agency (Christiansen, 2018).

Doumeizel (2018) finally stressed the issue of low income and margins in the food and beverage industry. In France and Western Europe, average share of revenue per household dedicated to food moved from $25 \%$ to $8 \%$ within 40 years. This in turn creates the problem of investment in the food supply chain and the balance in the revenue from food production. It was explained that, out of the 800 million people that are starving to death today, 700 million of them are farmers. So those who can and who should produce the food are the ones who are starving

\subsection{Maintenance Management Practices and Optimization Models applied in the Food and} Beverage Production System

Extensive work has been carried out on examining appropriate production maintenance strategies and optimization models for the manufacturing industry; whiles most works focus 


\section{MInstitute Macrothink $^{\text {Int }}$}

on exploring the importance of production plant maintenance, a lot more others have recommended preventive and corrective maintenance systems. With regards to maintenance optimization modelling, a significant number of works tend to focus on single decision variable such as minimizing total system cost, only a few have applied multivariable parameters especially for the food and beverage industry. This study therefore, fills this gap by modelling an optimized maintenance system, using two series multivariable analysis for the food and beverage industry production system.

A comprehensive and practical maintenance policy outline for managing industrial machines was stipulated by Badiru (2013) to include; lubrication of points of contact of the moving parts once every week to prevent ware and maintenance cooling conditions, recoating of peeled off protective coats to slow down rusting, prompt replacement of warn out parts, ensuring compatibility for instance by using the appropriate lubricating oil for the appropriate metal surfaces, conduct routine checks on electrical parts of machines to forestall potential faults and ensure proper connections, monitor and observe the functioning of machines during operations in order to identify symptoms of future breakdowns, limit machine running periods to avoid excessive overheating and ensure total overhauling of machine periodically.

In the same vein, Ohunakin and Leramo (2012) examined the implementation of total productive maintenance implementation in the Nigerian beverage industry and its implications for production performance. After investigating and collecting data on production losses in the firms, the total productive maintenance (TPM) Kaizen technique was adopted to eliminate these losses. It became evident that, just after a seven-day implementation of the TPM, the Overall Equipment Effectiveness and uptime increased by $50 \%$ compared with their existing maintenance methods.

Generally, maintenance optimization models encompass mathematical models that are focused on finding either the optimal balance between costs and benefits of maintenance or the most appropriate time to execute maintenance (Vasili et al., 2011). They presented an overview of existing maintenance optimization models. Types of maintenance policy identified are the preventive maintenance (PM); which consists of a set of management, administrative and technical actions to improve the availability and reliability of a system, corrective maintenance (CM); maintenance actions after the system breaks down and the Risk based maintenance optimization (RBMO); analyzes main objectives' influence on alternative sets of maintenance strategies, for each component. These policies have over the years been applied simultaneously for simulations and safety risks especially for static environments (Vasili et al., 2011). Main parameters emphasized in this optimization are the cost of failure, the cost per time unit of downtime, the cost (per time unit) of corrective and preventive maintenance and the cost of repairable system replacement.

Rivera-Gomez et al. (2018) investigated the optimal production and maintenance switching strategy of an unreliable deteriorating manufacturing system using their proposed new stochastic dynamic programming model where optimality conditions are derived through the Hamilton-Jacobi-Bellman equations. The deterioration process effects influenced the failure intensity and on the quality of the parts produced, and the rate of defectives depends on the 
production rate, thus integrating availability and quality deterioration led. A sensitivity analysis of the proposed joint control policy, indicated a significant influence by the deterioration of the machine (Rivera-Gomez et al., 2018).

Furthermore, (Thi et al., 2010) also proposed a model that takes into account the spare part inventory in the maintenance or replacement problem of a stochastically deteriorating system under technological change. It determined the maintenance strategy based on the parametric performance of the system and technological environment. It was observed that in the non-obsolescence case, the replacement is done only at low stock levels; on the contrary, at high stock levels, the maintenance options demonstrated their dominance. Therefore, a replacement option with new technology is motivated, but the trade-off between the spare parts utilization in store benefits and the revenues of investment in new technology was not overemphasized (Thi et al., 2010).

Finally, (Uzun and Ozdogan, 2012) reiterated the prevent technical and economic losses and increasing production efficiency, as resulting from the planning of manufacturing and maintenance activities together, creating a balance between maintenance and production parameters and developments on maintenance. Their study revealed how a genetic algorithm (GA) procedure is successfully applied to the integrated optimization model to determine optimum production policies based maintenance parameters. GA depends on computer programs to make optimization for integrated preventive maintenance and production planning (IPMPP).

\section{Methods}

According to Saunders et al. (2009), research must be conducted in a systematic manner drawing logical relationships and conclusions. Both the inductive and deductive research approaches were applied. Wilson (2010) defines deductive approach as developing a hypothesis based on existing theory, and designing a research strategy to test the hypothesis. This involves the application of scientific principles, explanation of causal relationships between variables and quantitative data collection. Inductive research is a theory-building process, involving observations generalizations about the phenomenon under investigation (Hyde, 2000, p. 83; Saunders et al., 2009). This research project adopted and applied a maintenance optimization model that explains the relationship between maintenance activities, spare part inventory and production quality output in Ghana's food and beverage industry, with the objective of making generalizations about cost and quality productions management.

The research applies mathematical models and methods to industrial case studies in the food and beverage industry of Ghana. First of all, it assesses the entire production processes of a typical food and beverage firm by trying to understand the demand rates that determine the work piece load for each production schedule, the capacity limits of the plants, and the production rate and cost. It goes further to research the maintenance acts, production quality control systems, maintenance spare part inventory management strategies, as practiced by food and beverage firms in Ghana and the challenges associated with maintenance practices. The above therefore provide the database to formulate the maintenance optimization problem, 


\section{Ml Macrothink}

model, analyze and solve them using mathematical modeling with the aid of the MATLAB software. Conclusions and generalizations about Ghana's food and beverage industry with regards to the relationship between spare part inventory, production quality and maintenance acts, as well as the best way to achieve optimal total production cost in the industry. Figure 7 summarily illustrates the afore-stated procedure.

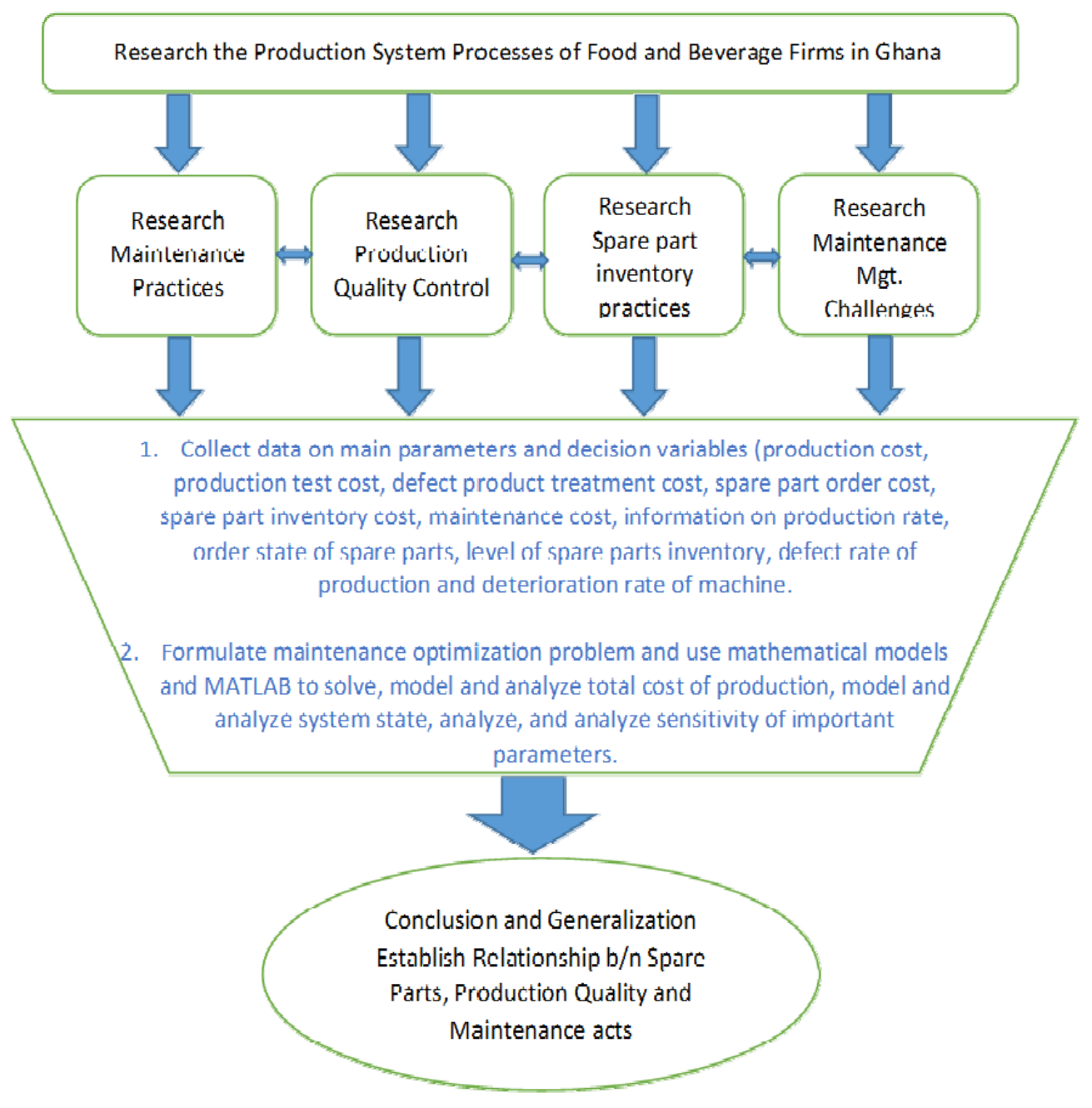

Figure 7. The Maintenance Optimization Research Strategy

\subsection{Data Source and Analytical Procedure}

This research depends heavily on the empirical generalization of a myriad of documentary secondary data and survey based sources. Using the research Triangulation method (Saunders et al., 2009) the study collected both qualitative and quantitative data from the available secondary sources. Relevant documentary secondary data for parameters and variables (as described in figure 3.1), for the proposed maintenance optimization model were accessed from written materials such as organizations' notices, financial statements, website, annual general meeting reports and memorandums. For reviewing literature, books, journals, magazine articles and newspapers were consulted. Survey-based secondary data sources also 
included government publications.

This study proposed a maintenance optimization model that considers the intercession of preventive maintenance, time of implementation of the preventive maintenance and remedial maintenance. For a given work piece scheduled by a demand rate forecast, the production plant processes of the selected food and beverage firms in Ghana was investigated and modeled. It considered the intercession of preventive maintenance, time of implementation of the preventive maintenance and remedial maintenance acts. The results were therefore analyzed using mathematical formulations with the assistance of MATLAB and Simulink Programming hub to model and optimize the system total cost.

Other quantitative and qualitative data derived about maintenance management challenges, production quality control strategies and spare part inventory management were analyzed as presented in the secondary data sources, supporting them with frequencies and percentages of occurrences, pictures, graphs and charts to enhance the discussions.

\section{Results and Discussions}

\subsection{Analyzing the Production Process of Ghana's Food and Beverage Industry}

The food and beverage processing business in Ghana entails a series of activities including processing and preservation of meat, fish, fruit, vegetables, oils and fats; manufacture of dairy products; manufacture of grain mill products, starches and starch products and prepared animal feeds; and manufacture of other food products, such as bread, sugar, chocolate, pasta, coffee, nuts, spices, local wine and fruit drinks. These operational trends in the industry signify a positive correlation with the main agricultural produce of the country: maize, rice, plantain, cassava, yam, fruit and vegetables (Table 1). Relative to the beverage production, food processing is carried out on a small scale. Some major food processing companies include ELSA Foods, Gracem Foods, Mannas Tropical Export and Kwanoye Ghana Co. Ltd.

Table 1. Trends in the production of Major Food Crops in Ghana (2004-2010)

\begin{tabular}{lrrrrrrr}
\hline Crop & \multicolumn{1}{c}{2004} & \multicolumn{1}{c}{2005} & \multicolumn{1}{c}{2006} & \multicolumn{1}{c}{2007} & \multicolumn{1}{c}{2008} & \multicolumn{1}{c}{2009} & \multicolumn{1}{c}{2010} \\
\hline Maize & $1,157,600$ & $1,171,400$ & $1,189,000$ & $1,219,600$ & $1,470,100$ & $1,619,600$ & $1,619,590$ \\
Rice paddy & 241,800 & 236,500 & 250,000 & 185,300 & 301,900 & 391,400 & 391,440 \\
Millet & 143,800 & 154,600 & 165,000 & 113,000 & 193,800 & 246,000 & 245,550 \\
Sorghum & 287,400 & 299,000 & 315,000 & 154,800 & 331,000 & 350,600 & 350,550 \\
Cassava & $9,738,200$ & $9,567,200$ & $9,638,000$ & $10,217,900$ & $11,351,100$ & $12,230,600$ & $12,230,630$ \\
Cocoyam & $1,715,900$ & $1,685,800$ & $1,660,000$ & $1,690,100$ & $1,688,300$ & $1,504,000$ & $1,503,960$ \\
Yam & $3,892,300$ & $3,922,800$ & $4,288,000$ & $4,376,000$ & $4,895,000$ & $5,778,000$ & $5,777,850$ \\
Plantain & $2,380,800$ & $2,791,600$ & $2,900,000$ & $3,234,000$ & $3,338,000$ & $3,563,000$ & $3,562,500$ \\
Groundnuts & 389,600 & 420,000 & 520,000 & 301,800 & 470,100 & 485,100 & 485,080 \\
\hline Total (mt) & $19,947,400$ & $20,248,900$ & $20,675,000$ & $21,492,500$ & $24,039,300$ & $26,168,300$ & $26,167,150$ \\
\hline
\end{tabular}

Source: Ministry of Food and Agriculture (2011) 


\section{MInstitute ${ }^{\text {Mink }}$}

This section enumerates the findings of the research survey derived from accredited media firm accounts in Ghana and the websites of the selected companies. The findings are presented and discussed with emphasis on the production processes, capacities and other related value chain activities of GIHOC Distillery Limited, Healthi-Life Ghana Limited and Parlays Ghana Limited in Ghana. Therefore, the section aims ultimately to ensure a wider scope of comparative analytical discussion and a valid database to formulate and solve the maintenance optimization problems of Ghana's food and beverage industry, using the proposed mathematical model.

\subsection{The Production and Value Chain Processes of GIHOC Distilleries Limited}

The production unit is the heart of GDCL and therefore it is a restricted area. The major goals and objectives of the department is to streamline their activities to commensurate with that of the organization; these included, producing within budget allocations, minimizing cost (energy, water and labour), avoid wastage of raw material (labels, cartons, glass), rotation of labour and prevention of injury. The company has only one production plant at its main location with factory building and expansion projects undertake and launched between the year 2013 and 2015 (Exhibit 1). This is made up of one dedicated production line for Castle Bridge and two other multi-production lines, which could produce either Mandingo or Herb Afrik. Production capacities are 40 pallets a day for the Castle Bridge line, 60 pallets for Herb Afrik and 50 pallets for Mandingo: each pallet holds 60 cartons. Although, it is general believed that there is more room for capacity expansion, the company is positive on its ability to meet the current demand if its products.

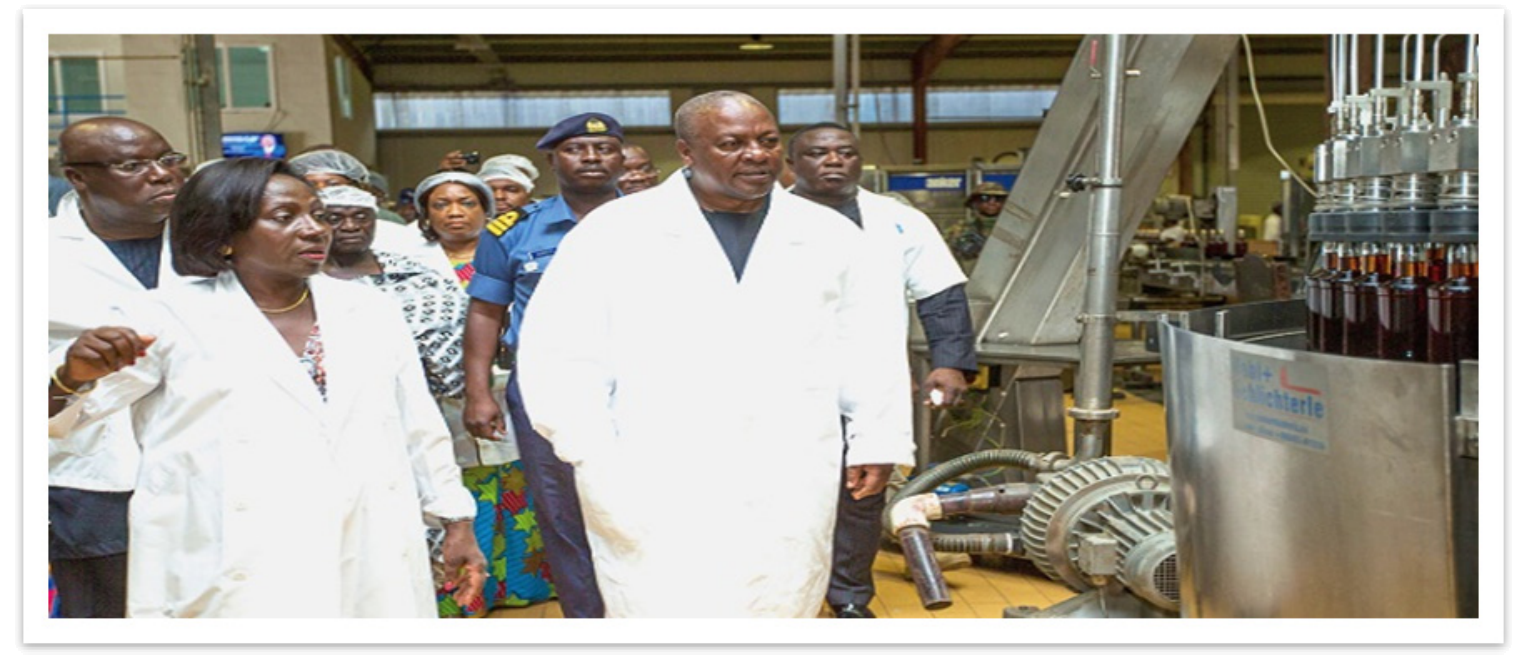

Exhibit 1. Factory Plant Expansion Project Inspection and Launching by the President

Source: www.gihocdistil.com

Maintenance activities are organized mainly by preventive and corrective (breakdown) measures. All aspects of the equipment are checked daily before production activities begin. The actual production of any product generally takes 45 minutes. Long term production 


\section{Macrothink Institute ${ }^{\mathrm{TM}}$}

schedules are reprogramed into daily work plans. The preliminary stage of the production process begins with the washing of available bottles using a bottle washing plant with a capacity of twenty-five thousand $(25,000)$ bottles per hour (Exhibit 2). Plant root are dried, grinded and immersed into alcohol for about 7days before blending is carried out, which involves the mixing up of roots, alcohol and flavor. The bottles are then moved to another point where they are filled with various mixtures to volumes of $700 \mathrm{ml}, 250 \mathrm{ml}$ or $500 \mathrm{ml}$ depending on the product and the bottle size (Exhibit 2). The filled bottles are moved further for capping, sealing and labeling (Exhibit 3). They are finally packed into cartons, arranged on pallet and stored on demarcated areas in the production unit waiting to be transferred to the finished goods warehouse.
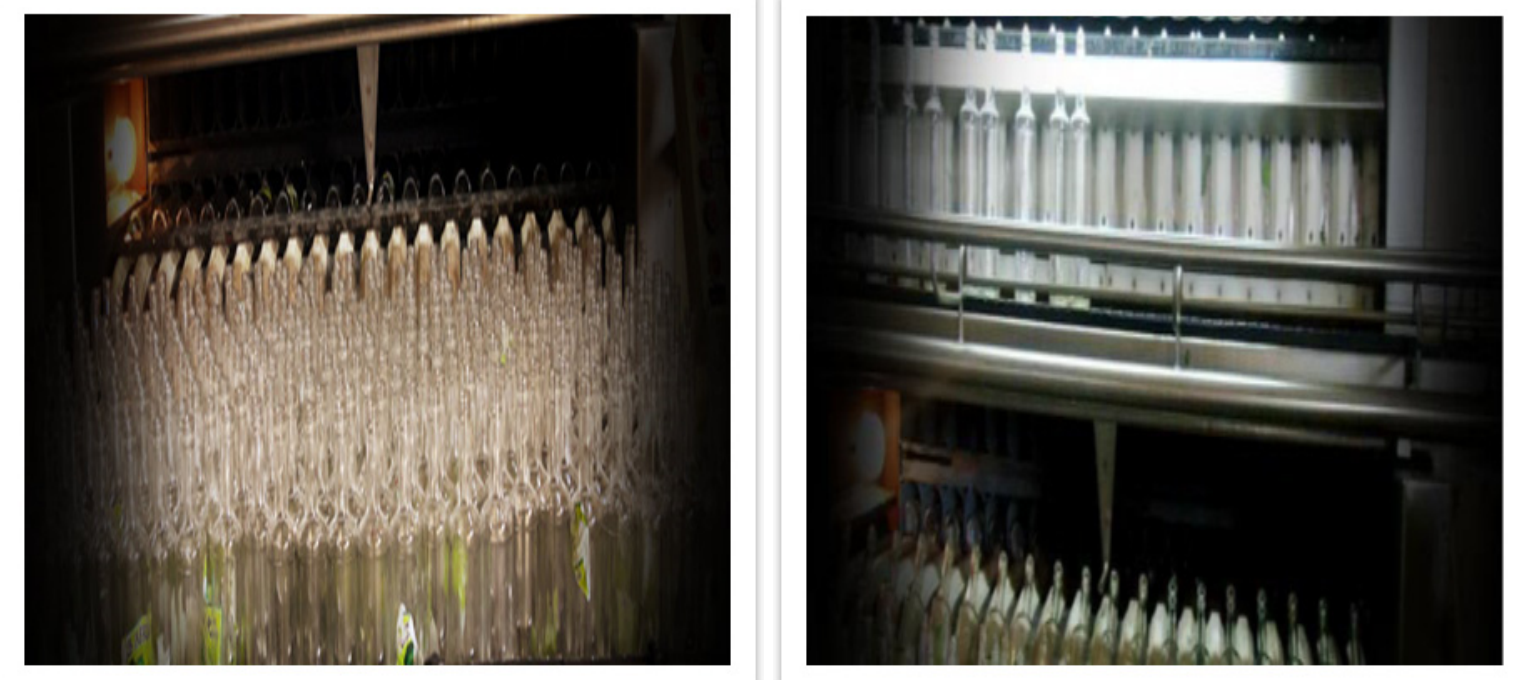

Exhibit 2. Bottles being Washed and being filled with different blends.

Source: www.gihocdistil.com 


\section{$\triangle$ Macrothink}
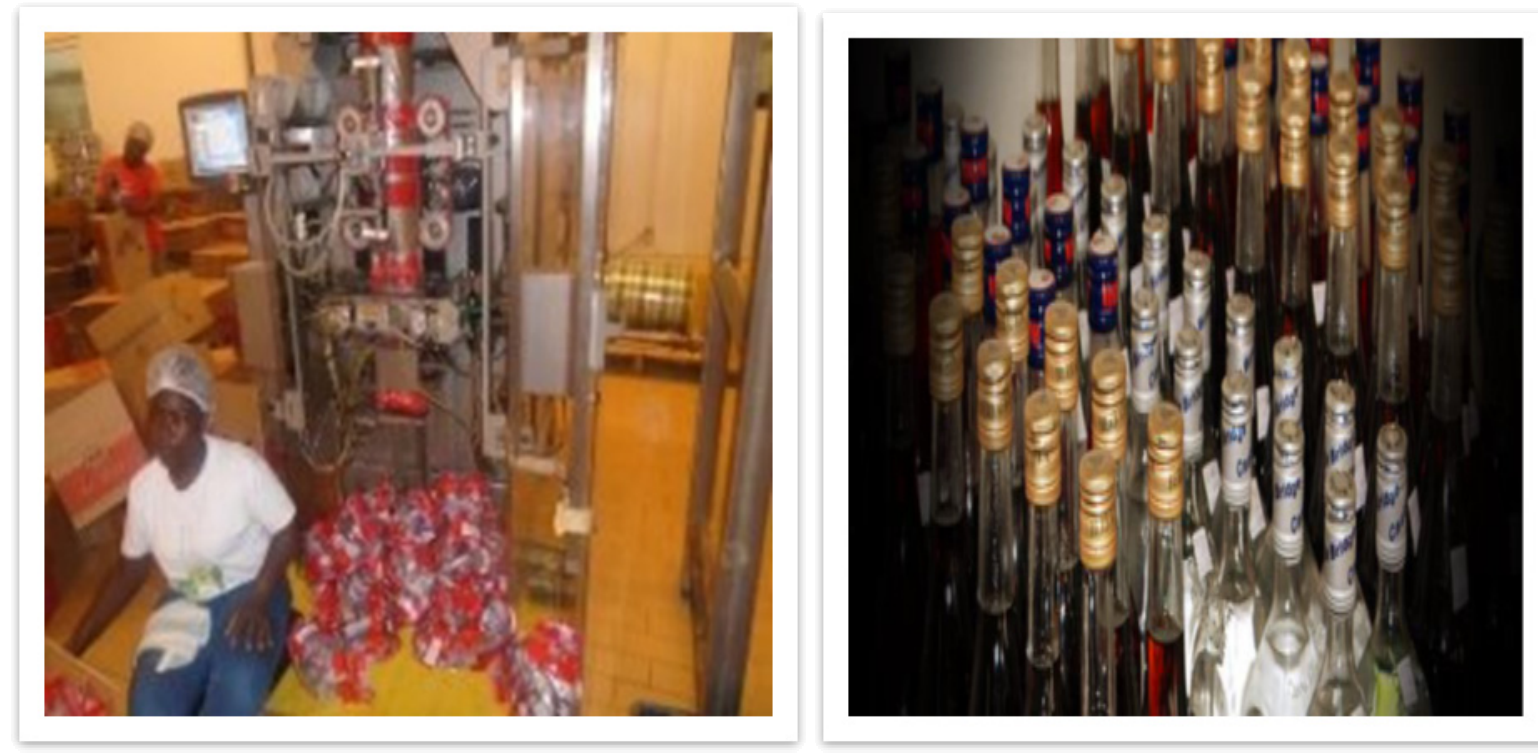

Exhibit 3. Bottle and Carton labeling, Filled, sealed \& labeled bottles

Source: www.edaifgh.org, www.gihocdistil.com

Marketing and sales. The marketing and sales department of GDCL targets two major tasks; getting new supply chain customers and end consumers, as well as marketing and selling of its product. Their products; Gin; Castle Dry Gin, Schnapps; Kaiser, Brandy; Chevalier, Bitters; Alomo, Mandingo, Herb Afrik, Liqueur; Takai, Buccaneer Rum, Vermouth; Sorrento (Exhibit 4.4) are sold in Ghana, Togo and Nigeria. GDCL owns one sales outlet in its premises. Alcoholic beverage sales volume increased from 5.4 million litres in 2010 to 8.2 million litres in 2014. The company has regional managers or sales representatives in each of their target markets, who have route scheduling plans to check stock levels of key distributors, generate order, help redistribution if required and make sure distributors make payment on time. Sales representatives also visit retailers to monitor sales turnover and as well identify their challenges. The company market itself and brands mainly through promotions, advertisement billboards, posters, ABS panels, flags, branded vehicles, branded T-shirts for employees and external customers, pens, cups and wristbands. Several advertisements have been done on radios and television stations. Moreover, the company sponsors programmes and projects during festivals; Kwahu, Oda, Odwira, Winneba, and Asogli and Hogbetsotso and other holidays. Sampling promotions are also implemented to check consumers' acceptance. 


\section{$\Lambda$ Macrothink}
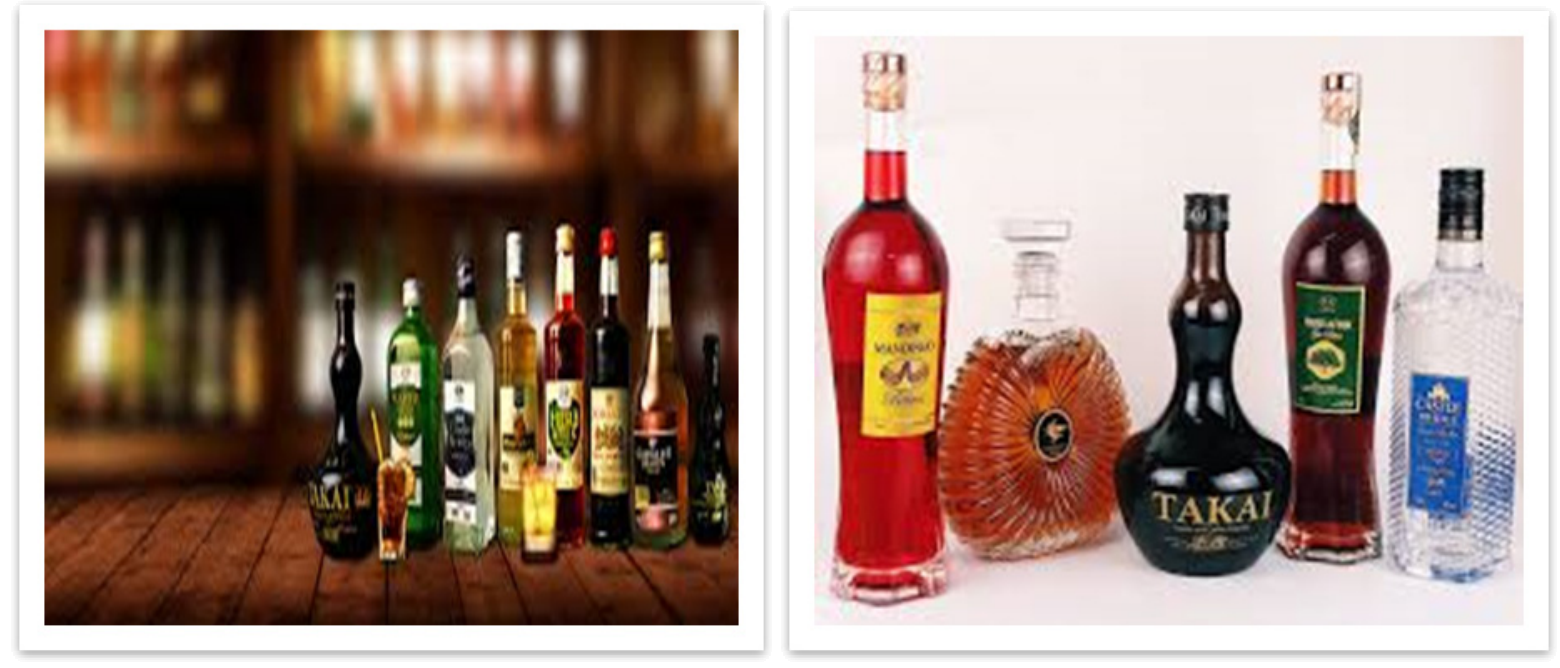

Exhibit 4. Product Brands of GIHOC Distilleries Company Limited

Source: www.edaifgh.org, www.gihocdistil.com

Procurement. The procurement department of GDCL is vibrant and resilient. Its ultimate goal is to ensure continues production system by procuring quality materials at the right price, time and place. The company has international and national supplies from Europe, Asia and Africa. Alcohol is procured from France, seals and cork are bought from Italy. Bottles are sourced from China. Cartons are from Tema and Accra. Whiles plant roots and fruits are also sourced from Accra and Tema. Production spare part inventories are also sourced both from international and local sources depending on the maintenance activity. It takes one day to complete all purchasing processes for materials that could be sourced locally. But at least one day for materials sourced internationally. There are no alternative suppliers of key inputs. However, backups for inputs materials are kept at the organizations warehouse or with the suppliers. The sourcing and bidding process are done via the internet. Major challenges facing the procurement department is the effect of exchange rate on budgetary allocations.

\subsection{The Production and Value Chain Processes of Healthi-Life Ghana Limited}

Healthi-life Beverages Limited was founded in 2008 with Mr. Kofi Nsiah Poku as executive chairman. It produces its own brand of several juice drinks and milk products. The company is at the forefront of producing high quality beverages with its main goal as enhancing overall health and productivity of its consumers. The company Logo contains an image of a running (exercising) person which is in a bid to emphasize healthy living. Healthi-Life is part of the Kina Group of Ghana-based international companies. It is a very celebrated brand in Ghana and is known for its juices, milk product made for both children and adults. Healthi-Life operates in all the 10 regions of Ghana with their depots in Accra, Kumasi, Takoradi, and Tamale (www.healthilife.com). 


\section{Macrothink}

As its vision, Healthi-life aspires to be the preferred choice in the food and beverage industry for consumers across Africa. It plans to penetrate all major markets in sub-saharan region in the next 10 years. Using environmentally friendly and state of the art technology, the company's mission is to produce tasty, nutritious and good value for money products. Aside employing staff in Ghana, sierra Leone and Liberia, in Nigeria Healthi-Life has experienced distributional growth throughout the country as far as to Kano and Kaduna. The Healthi-life beverage Limited has products for all age groups. Some of their products includes juice drinks, energy drinks, milk and flavored soy milk (Exhibit 5). These range of products make it possible for adults to appreciate the vitamin and calcium enriched contents while children enjoy the flavor. Healthi-Life has nearly one thousand staff strengths in Ghana, Nigeria, Sierra Leone and Liberia. Its staff is the greatest asset the company possess as it comprises a team of experts who meticulously give their best (www.healthilife.com).
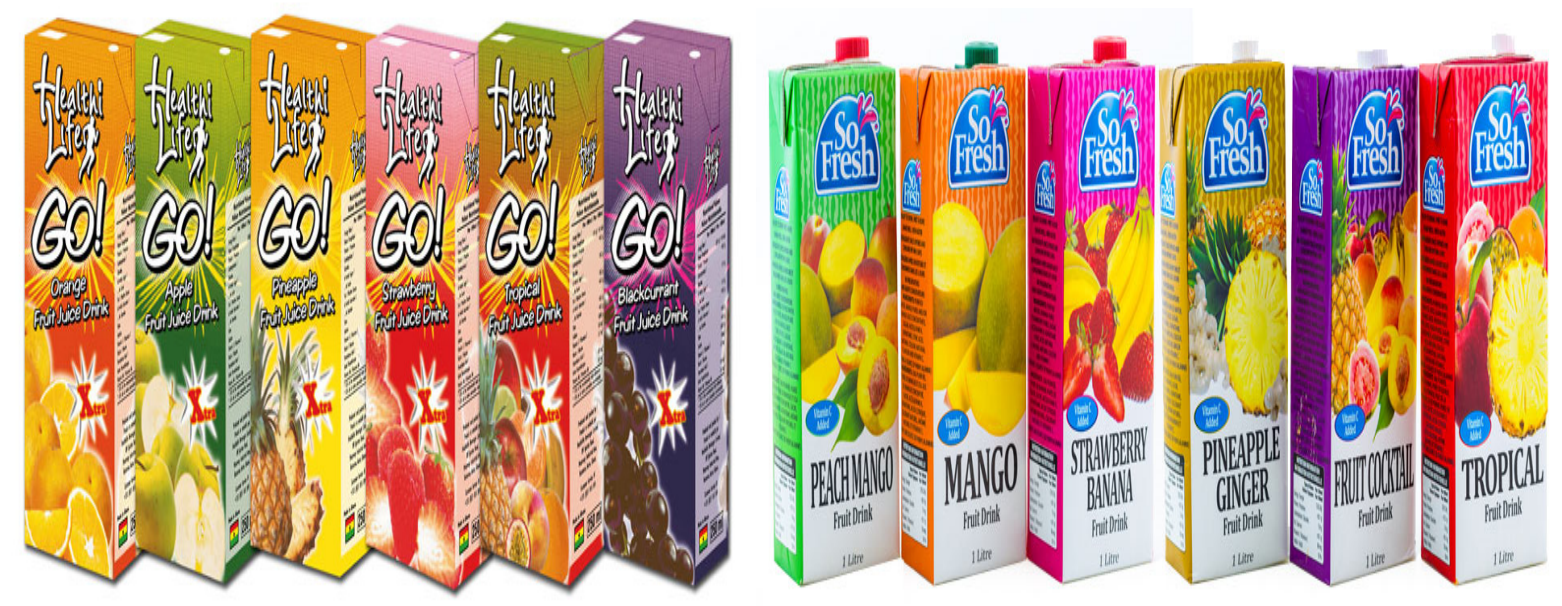

Exhibit 5. Product Brands of Healthi-Life Ghana Limited

Source: $w$ ww.healthilife.com

The company's factory can be described as one of the biggest, state of the art, fully automated, 5 -line tetra pak facilities in sub Saharan Africa. It is in this sophisticated factory that all the production process takes place from blending to packaging. The factory is large and advances with a strong employee base, hence giving healthi-life the capacity to supply enough to meet demand in the whole of Africa. No preservatives are added during production in effect keeps the product natural and packaged in such a way that bacteria attack is absolutely prevented (www.healthilife.com).

In terms of marketing its products, Healthi-Life employs various forms of Radio and TV commercials as well as print advertisements. The possibility of having sweet but healthy beverages is emphasized in all their adverts. As part of its advertisements, Healthi-Life uses Jingles which includes 'chocovita jingle', 'Go Xtra Jingle', 'Premium Jingle', 'Gluconade Jingle' and the 'pure jingle'. A critical look at these strategies of marketing shows a 
promising ability to leave a long-term mark in the minds of consumers which translates into higher sales. With these marketing strategies, it is not surprising for healthilife to be a famous brand in Ghana and parts of Africa. But can these strategies enable them to thrive in a market outside Africa like the European or Asian market?

\subsection{The Production and Value Chain Processes of Parlays Ghana Limited}

Parlays Ghana was founded in 1993 by Dayou Purswani, an Indian who has lived most of his life in Ghana and was educated at the University of Ghana, Legon. Located on the Spintex Road, in one of Accra's industrial areas, the company is the second largest biscuit manufacturer in Ghana. The company is a family business managed by the owner and his wife with over 200 employees, of which $60 \%$ are casual workers. In 1993, Dayou Purswani was the sole distributor of Burton Biscuits (one of the largest biscuit manufacturer in the UK) on the University of Ghana campus. Through the distributorship, he observed a huge untapped market and demand for biscuits in Ghana and conceived the idea of manufacturing his own line of quality biscuits. Equipment was procured from India to produce biscuits in Ghana to test the market in 1995. The company employed one chemist (to help ensure that the biscuit mixture was accurate), one engineer (to man and service the equipment) and a few additional staff who helped with the sealing and packaging of the biscuits. The process at that time was manual and the wrappers were sealed with hot plates. Given the manual processes, production volumes were very low: only $2 \mathrm{mt}$ of biscuits per day. The trials were successful and within a few months' demand for the company's biscuits grew, necessitating the purchase of additional equipment. Using a building that he inherited as collateral, he secured financing from the Ghana Leasing Company to acquire a complete biscuit production line in 1995. That same year, the company, Parlays Biscuits Ghana, was officially registered (Sutton and Kpentey, 2012).

Current activities and products. Parlays Biscuits manufactures 12 different kinds of biscuit: Parlays Glucose Biscuits, Parlays Digestive Biscuits, Parlays Cream Crackers, Parlays Shortbread, Parlays Gem Biscuits, Parlays Ginger Biscuits, Parlays Coconut Biscuits, Parlays Chocolate Biscuits, Petit Biscuits, Mmofra Mmofra Biscuits, 15 Glu Glu Biscuits and Malt \& Milk Biscuits (Exhibit 6). These biscuits are packaged in packs of four, six and eight. The company currently produces 300 bags of biscuits a day. As part of its marketing strategy the company uses celebrities to promote its products. Parlays biscuits became famous in Ghana when one of Ghana's most celebrated footballers, Abedi Pele, appeared on the wrappers and in the company's advertisements. This improved the company's brand image, resulting in increased sales. A similar strategy was successfully used when wrappers were branded with the name of Emmanuel Adebayor, one of Togo's best football players, for biscuits the company exported to Togo. The production process of the company is depicted in figure 4.1 and Exhibit 4.7 (Sutton and Kpentey, 2012). 


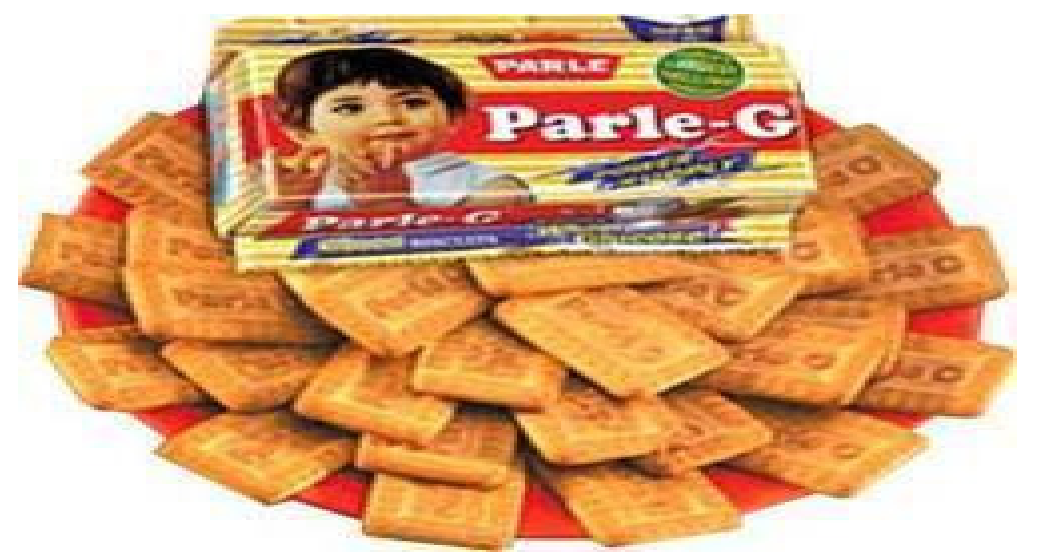

Exhibit 6. Product Brands of Parlays Ghana Limited

Source: www.google.com

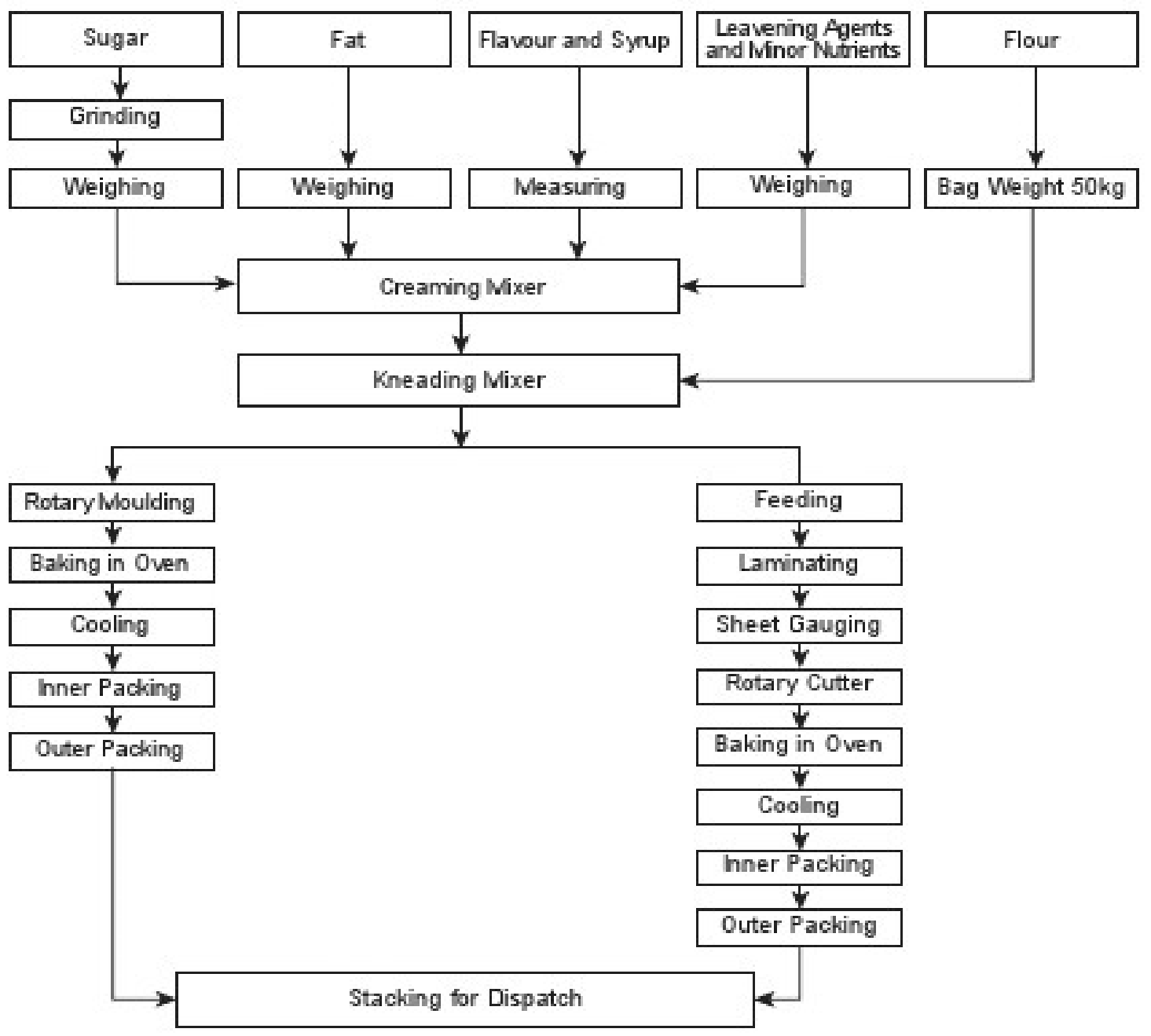

Figure 8. Production process at Parlays Ghana Limited

Source: Sutton and Kpentey, 2012. 


\section{Macrothink}

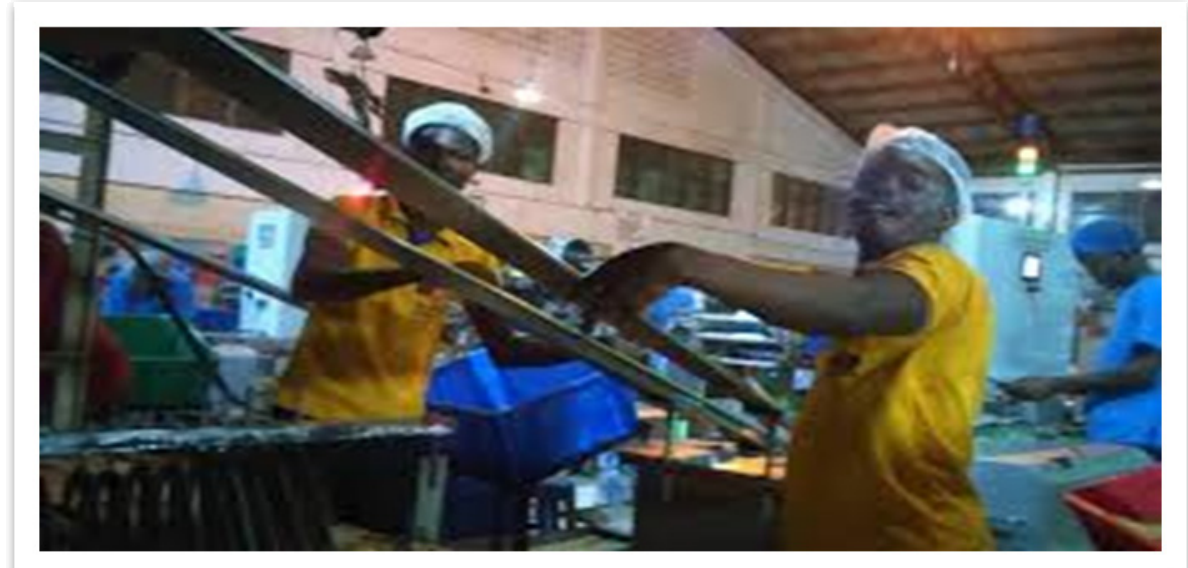

Exhibit 7. Product Brands of Parlays Ghana Limited

Source: $w w w . g o o g l e . c o m$

Organization and management. The managing director and founder reports to the board of directors. He is supported by managers responsible for finance, manufacturing and administration. Departments have some degree of autonomy for decision making. DevyaniPurswani, who is one of the directors of the company, manages the distribution team and wholesalers (Sutton and Kpentey, 2012).

\subsection{Maintenance Management and Engineering Systems Deployed in Ghana's Food and} Beverage Industry

The maintenance culture of Ghana's food and beverage industry is quite strategic in maintenance planning but less than optimal in maintenance practices and outcomes. Telang and Telang (2010) identified four main sectors of Ghana's manufacturing industry, namely woodworking, food processing (23\%), metal working and textiles and garments, and analyzed their maintenance systems and strategies in-house relative to contract Maintenance/repair. There is increasing trend of using contract maintenance by manufacturing companies across the globe in the last few years, especially among larger firms. In addition, about sixty percent of large enterprises and medium enterprises conduct $70 \%$ of their maintenance and repair work in-house, giving preference to contractors in Ghana., and only three percent of firms conduct $50 \%$ of their work in-house (Figure 9). 


\section{Macrothink}

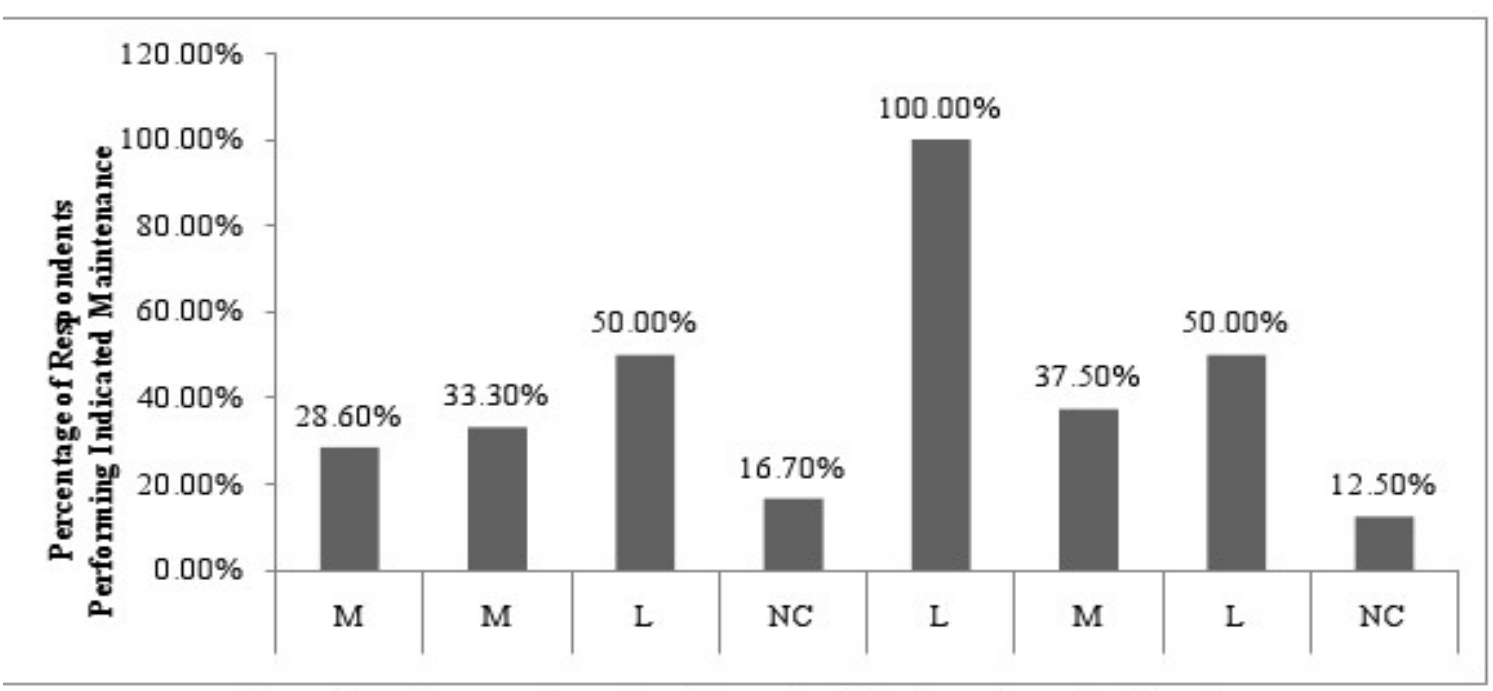

Figure 9. In-house Maintenance/Repair works based on firm size

Source: Telang and Telang (2010)

Moreover, Ribeiro et al. (2015) conducted a rather comprehensive survey based analysis of the production scheduling and preventive maintenance planning systems and strategies, of the manufacturing industry in Ghana as well as the equipment and devices used (Figure 10, 11 and 12). It was revealed that, the production plan and maintenance actions directly affect the workstations' operation schedules. In that, planned preventive maintenance schemes are mainly employed because they are the best suited to the equipment types employed by respondent firms. Gaining optimal values in production quality and maintenance acts was considered almost unattainable; which resulted in an unsatisfied demand in production due to the interruptions from the preventive maintenance interventions or workstation failures. Total Productive Maintenance (TPM) received a rather low application mainly by medium and large scale enterprises, representing only (6.7\%). This was attributed to high cost of its implementation. Meanwhile, TPM is $b$ believed to promote cost reduction while improving the quality and overall delivery of the maintenance function (McKone et al., 2001; Ribeiro et al., 2015).

It was further observed and derived from the project survey that a chunk of firms practice hybrid system of production maintenance; employing more than one maintenance strategy for all equipment. They combine different strategies, as needed, to suit their production and equipment schedules (Ribeiro et al., 2015). 


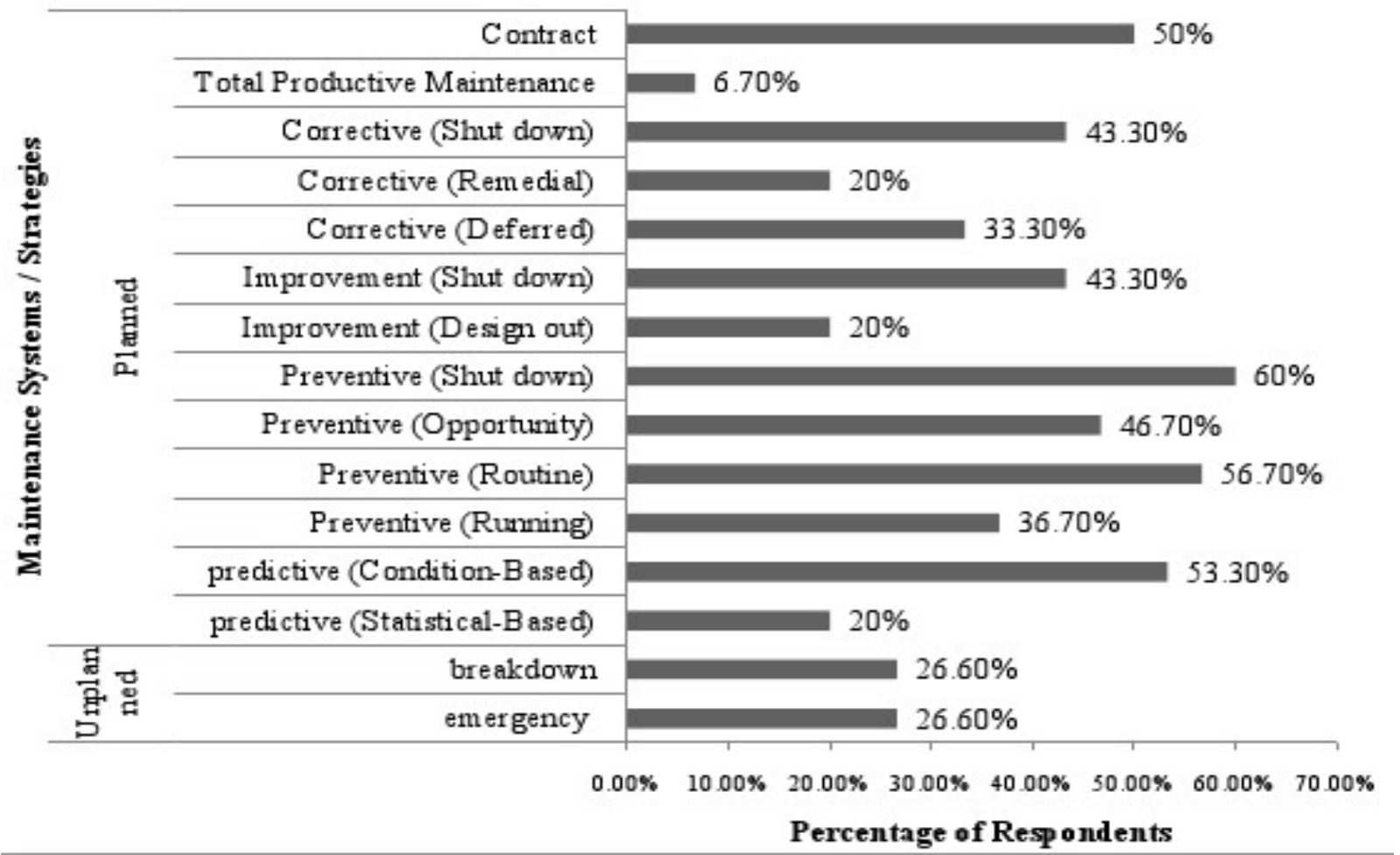

Figure 10. Maintenance systems and strategies utilized by manufacturing firms in Ghana

Source: Ribeiro et al. (2015)

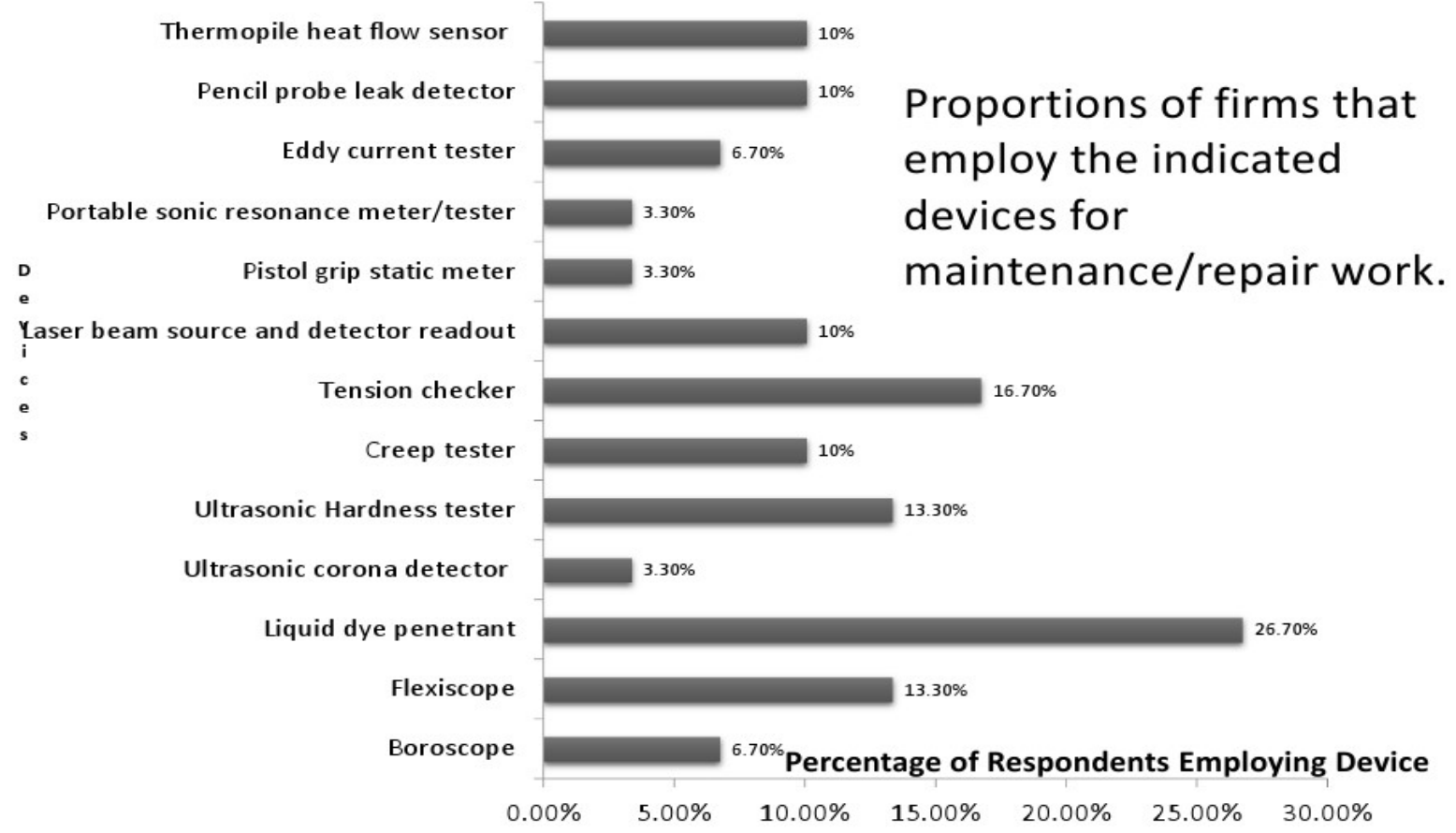

Figure 11. Maintenance/Repair Devices used by manufacturing firms in Ghana

Source: Ribeiro et al. (2015) 


\section{Macrothink}

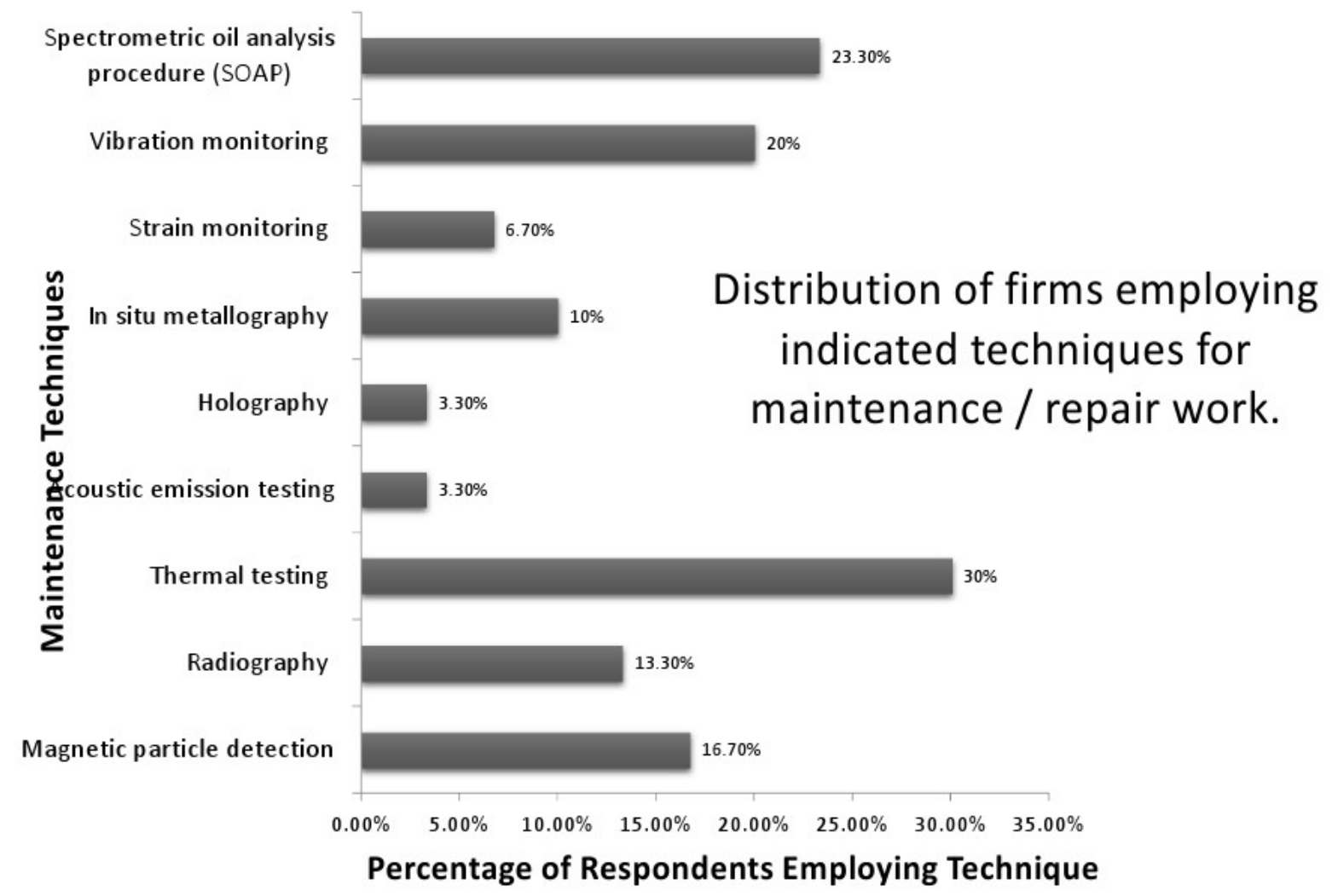

Figure 12. Maintenance/Repair Techniques used by manufacturing firms in Ghana

Source: Ribeiro et al. (2015)

\section{Spare Part Inventory Capacity and Production Quality Control Systems in Ghana's Food and Beverage Industry}

Although firms in Ghana's food and beverage industry have realized the strategic essence holding adequate spare part inventory in order to ensure a seamless quality production process and output, it is often a crucial management decision to take especial with regards to obtaining an optimal balance between inventory capacities, maintenance acts and production quality. Agyei-Boahene (2010) typified a breakdown of the different times that the various category of factories that produce drinking water use per production session (Table 2). While the sachet water packers work within an eight-hour session, the bottled water and other product lines are more targets oriented; each group or person has a set target they are supposed to meet during their sessions. Hence, despite each category, there is a general consensus among the company workers that there is the need for raw materials to be stored on site and used as and when needed. Again, the production floor must be structured such that there is easy movement from one machine to another, otherwise firms may require a total change in machinery that can produce a better quality product in less time and with less cost. 


\section{Macrothink}

Table 2. Relationship between Production Batch Duration, Inventory Management \& Production Methods

Source: Agyei-Boahene (2010)

\begin{tabular}{|c|c|c|c|c|c|}
\hline & & \multicolumn{3}{|c|}{ Inventory Management and production methods } & \multirow[b]{2}{*}{ Total } \\
\hline & & $\begin{array}{c}\text { storage of large } \\
\text { quantities of stock to } \\
\text { meeting production } \\
\text { demands }\end{array}$ & $\begin{array}{l}\text { ordering of raw } \\
\text { materials as and } \\
\text { when needed }\end{array}$ & no response & \\
\hline \multirow{5}{*}{$\begin{array}{l}\text { Duration of production } \\
\text { batches }\end{array}$} & less than an hour & $15.0 \%$ & $5.0 \%$ & $.0 \%$ & $20.0 \%$ \\
\hline & $1-3$ hours & $10.0 \%$ & $.0 \%$ & $.0 \%$ & $10.0 \%$ \\
\hline & $4-6$ hours & $10.0 \%$ & $.0 \%$ & $.0 \%$ & $10.0 \%$ \\
\hline & more than 6 hours & $50.0 \%$ & $.0 \%$ & $.0 \%$ & $50.0 \%$ \\
\hline & no response & $5.0 \%$ & $.0 \%$ & $5.0 \%$ & $10.0 \%$ \\
\hline \multicolumn{2}{|l|}{ Total } & $90.0 \%$ & $5.0 \%$ & $5.0 \%$ & $100.0 \%$ \\
\hline
\end{tabular}

Delving further into analyzing the quality control tools chosen and implemented by firms in the food and beverage industry in Ghana, existing data as indicated from a survey conducted by Edu (2013) showed that a majority $(23.6 \%)$ of firms use Flow charts. Eleven firms, representing 20\%, use Statistical Control Charts to identify products defect. The result further indicates that $16.4 \%$ of the firms use Check Sheet in identifying products defects. Again, 3 firms, representing 5.5\%, indicated to be using Pareto Charts and Scatter diagram. Only 1 firm however, indicated the use of Fish Bone diagram for detecting quality problems. Out of the 55 firms interviewed, 8 firms did not response to these questions. In addition to the seven main production quality control tools, the bar charts represented the most common tool used by these firms, with a percentage of $49 \%$, followed by acceptance sampling with $36.4 \%$. Some firms also use Pie charts, Line graph and System Process Audit (see figure 4.5). 


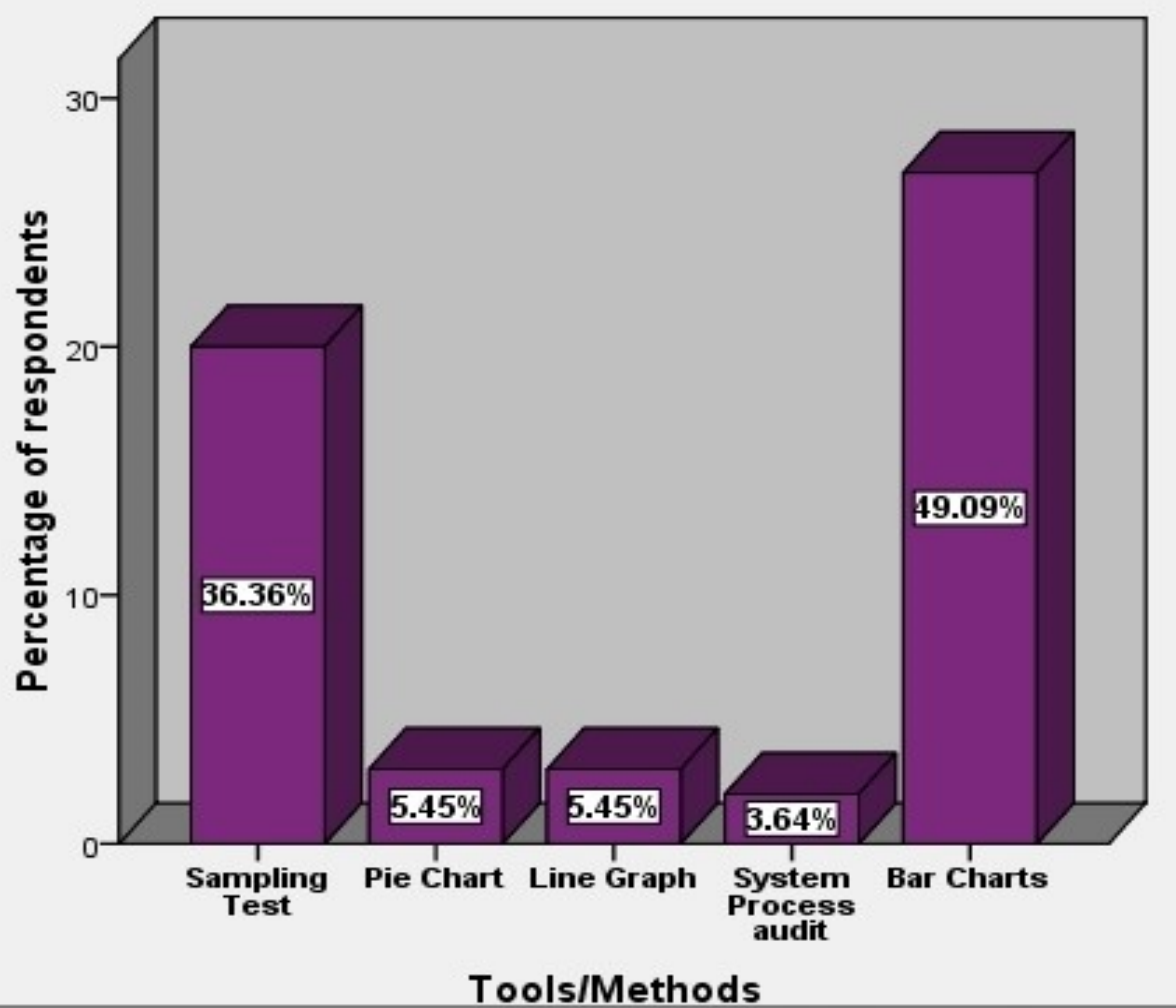

Figure 13. Other Quality Control Tools used by Ghana's Food \& Beverage Industry

Source: Edu (2013)

The survey further revealed the total quality management (TQM) strategies deployed by firms in Ghana's food and beverage industry. Majority of firms emphasized the maintenance of production equipment per the maintenance operation plans developed as well as the conduct of meticulous and effective inspection practices for raw materials, in-progress good and finished goods, in order to identify defective products and direct them for treatment (see Table 3). 


\section{Macrothink}

Table 3. Process Control \& TQM practices in Ghana's Food \& Beverage Industry

Source: $E d u(2013)$

\begin{tabular}{lccccc}
\hline & $\begin{array}{c}\text { Strongly } \\
\text { Disagr ee }\end{array}$ & Disagr ee & Neutral & Agree & $\begin{array}{c}\text { Strongly } \\
\text { Agree }\end{array}$ \\
\hline $\begin{array}{l}\text { Items } \\
\text { Our firm is kept neat and clean at all }\end{array}$ & 0 & 0 & $25 \%$ & $45 \%$ & $30 \%$ \\
$\begin{array}{l}\text { Process capability meets production } \\
\text { requirements }\end{array}$ & 0 & 0 & 0 & $65 \%$ & $35 \%$ \\
$\begin{array}{l}\text { Production equipment is well } \\
\text { maintained according to the }\end{array}$ & 0 & 0 & 0 & $10 \%$ & $90 \%$ \\
maintenance plan & & & & & \\
$\begin{array}{l}\text { Our firm implements various } \\
\text { inspections effectively (e.g., } \\
\text { incoming, process and final products) }\end{array}$ & 0 & 0 & 0 & $25 \%$ & $75 \%$ \\
$\begin{array}{l}\text { Our firm uses Deming Wheel } \\
\text { extensively for process control and } \\
\text { improvement }\end{array}$ & $25 \%$ & $45 \%$ & $5 \%$ & $15 \%$ & $10 \%$ \\
\hline
\end{tabular}

Another survey conducted for a renowned beverage company in Ghana; Kasapreko Company Limited, showed very interesting results about the Quality Assurance (QA) systems, which were based on quality control, process monitoring and end product testing operation of firms in the industry. Generally, about $90 \%$ of production managers attribute quality to high cost. Although the Company's QA system which is an aspect of Quality Management Systems (QMS) is maintained in accordance with best industry practice, quality manual and documented standard operating procedures (SOP) to promote due diligence in its operational activities, it does not entirely conform to the requirements of ISO 9000: 2005 and ISO 9004:2009. Refer to table 4.4 (Quaye, 2016). Administrative measures were effective, with the daily generation of documents and completion of records for planned activities, maintenance and verification. Product testing was based on the Codex Alimentarius guidelines, which aimed at assessing the quality and safety level of finished product prior to distribution. Traceability systems have been established and maintained. Non-conforming products are either discarded or reworked based on an internal SOP (Quaye, 2016). 


\section{Macrothink}

Table 4. Quality Improvement Practices in Ghana’s Food \& Beverage Industry

Resp onses

ISO 9000

Quality control / Quality Assurance

Quality Management Systems

Total Quality Management

Total

\section{Frequency}

Source: Quaye (2016)

\section{Assessing the Challenges of Production Plant Maintenance Management in Ghana's Food and Beverage Industry}

Notwithstanding the efforts of firms in Ghana's food and beverage industry to ensure efficient and quality production systems that generate quality output through effective maintenance practices, presented in previous sections of this chapter, the complexity of the entire process renders optimality a great challenge. Whiles most firms have consistently sought to find optimal solutions to their production maintenance activities, they have been continually bedeviled with some of these challenges. This section presents results related to the challenges faced by firms in Ghana's food and beverage industry.

A study conducted by Ribeiro and Sackey (2014) explained that maintenance/repair activities in the manufacturing sector of Ghana are virtually without the use of modern tools and techniques. This was mainly as a result of lack of expertise to use and calibrate these tools and system, the high cost of acquiring the maintenance equipment and tools coupled with their unavailability within Ghana, long-term manifestation of the outcome of using these equipment, and the general inability of production managers to appreciate the importance of these tools and techniques, and their place in equipment maintenance (Ribeiro and Sackey, 2014).

Moreover, some other challenges associated with implementation of TQM that are faced by firms in Ghana's food and beverage industry were identified by Edu (2013) to include; inefficient communication of quality policy to staff, lack of understanding the concept of TQM, inadequate resources to educate and train staffs, quality of raw materials from suppliers, machine maintenance culture, unwillingness of staff participation during production, cost of ensuring quality is expensive, management do not meet regularly in discussing quality issues, and the limited employee participation because of level of 
education.

Ribeiro et al. (2015) were quite explicit in outlining the challenge of implementing maintenance strategies furthermore. These included; cost of shut-downs, cost of spare parts, failure of maintenance staff to retain knowledge and skills after training, insufficiency of funds allocated to the maintenance function, and reluctance of contractors to replace defective parts. A common ramification of these challenges is that when production resumes after a shut-down, equipment generally operate sub-optimally, leading to a significant portion of first production turning out defective. Again, the increasing cost of spare parts, coupled with delays in their delivery affects the cost-effectiveness of the maintenance function. Finally, the reluctance of maintenance contractors in Ghana to replace defective parts poses a major challenge to maintenance practices, where spare parts supplies and replacement are delayed unduly, thus increasing overall production costs (Ribeiro et al., 2015).

\section{Formulating the Maintenance Optimization Model}

The optimal aim of this model is to minimize the total maintenance cost and the total time for conducting preventive and corrective maintenance activities in the industry. Variables to be controlled include the demand rates, production rate and production period. In modeling the maintenance optimization problem, it is advisable to use series of Fourier, Saw-tooth type as shown below. Fourier analysis studies involve the transformation of general functions into trigonometric or exponential functional sets with specific and consistent frequencies (Morin, 2009). Two main types of Fourier expansions are the Fourier series and the Fourier transform. As a model for emphasis in the modeling of the maintenance optimization problem of Ghana's food and beverage industry, the Fourier series is preferred because, it follows a systematic and consistent periodic function which can be formulated using specific frequencies in discrete sum of trigonometric or exponential functions (Morin, 2009). This function is similar to the pattern adopted for preventive and corrective maintenance practices by firms in the industry. Fourier transform on the other hand does not necessarily have periodic patterns but however show a somewhat consistent behavior that can be formulated with a group of possible frequencies into a continuous integral of trigonometric or exponential functions (Morin, 2009).

Let us consider a function $f(x)$ that is pertodtc on the trterval $0 \leq x \leq L$. Therefore, assuming a periodicity of $0 \leq \leqslant \leq L$, Fourier's theorem stated as a trigonometric series of function $f(x)$ can be formulated as shown in Morin (2009) below;

$$
f(x)=a_{0}+\sum_{n=1}^{\infty}\left[a_{n} \cos \left(\frac{2 \pi n x}{L}\right)+b_{n} \sin \left(\frac{2 \pi n x}{L}\right)\right]
$$


Where $a_{n}$ and $b_{n}$ coefficents takes on particular values that fits the function $f(x)$. Although, it is conventional to always isolate the $a_{0}$ term, it is possible to embed it in the summation allowing the sum to run form $x=0$ to $\infty_{r} \operatorname{strce} \cos (\theta)=1$ and $\sin (\theta)=0$. In addition, given $2 \pi$ as part of the trigonometric function, the term $n=1$ have a period $L$, which is the highest attainable and $n=2$ have a period $L / 2$, which follows in that manner (Morin, 2009). Consequently, we derive a saw tooth-tooth type Fourier series function as per the parameters identified and defined in section 5.3 for the maintenance activities on production plant components as shown in equation (2) below. According to Stillwell (2013) the component represented by the variable $x(t)$, is a periodic descending function, expressed as a function of time. Each period represents the production component's replacement.

$$
\begin{aligned}
& x(t) \\
& -\frac{2 g}{\sigma} \sum(-1)^{(N-1)} \sin \frac{N \sigma t}{\sigma} \ldots
\end{aligned}
$$

By substituting the price of excess production activities related maintenance activities $\left(P_{E}\right)$, into equation (2) we have;

$$
\begin{aligned}
P_{E}(t)=\frac{P_{N}}{1.5}+ & \frac{P_{N}}{2} \sum_{W=1}^{2000} \frac{(-1)^{(W)}}{N} \operatorname{Stn}\left[\frac { N \sigma t } { G } \left(t+\frac{A U_{W}}{2}\right.\right. \\
& \left.\left.+B T_{W}\right)\right] \ldots(E q .3)
\end{aligned}
$$

It would be realized that, equation (2) is exponential but equation (3) is a decreasing function. Consequently, equation (3) is further modified to ensure that the amplitude of equation (3) varies positively and negatively. It is therefore necessary and sufficient to note that $P_{E}(t)$ remains positive. Considering the number of terms in equation (3) from 1 to 2000, differing in unit, add the terms ${ }^{\frac{A W_{K}}{2}}$ and $B T_{W}$ to denote the phase angle in the function. The total price of excess item can be deduced as;

$$
P E_{S}=\sum P_{E}(t)
$$




\section{IIMacrothink}

We must know that the price of preventive service in a function of items is what gives the sum of excess price of an item as shown in equation (5);

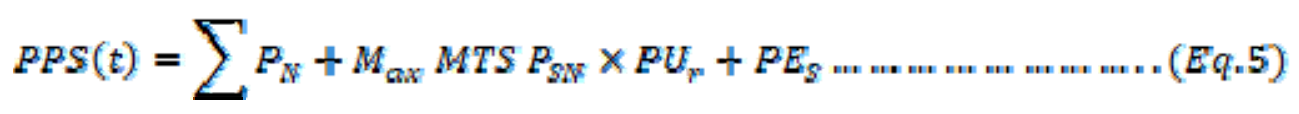

The price expeditious service takes the exchange of all items. The system simulates many frequencies. The $B T E_{V}$ is the variable that suck up the maximum items, hence the $B T E_{V}$ is far bigger than the maximum of a purposive item in an evaluated system.

The smallest series calculated is resolved by quarter of the value of the small-scale determined as in equation (6);

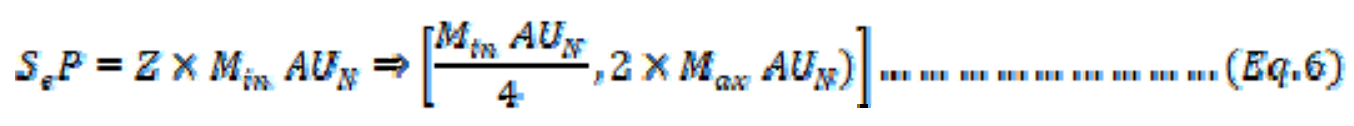

Per each series calculated within the range defined in equation (6), we get the cost of preventive service function of the series. We further deduce equation (7) from equation (6) where $Z$ is the increment factor of 0.5 .

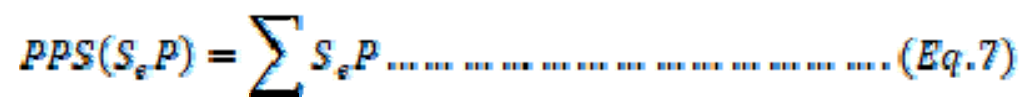

We must note that as the series increases, the cost of maintenance gets another variable, generated by remedial events. The remedial event can be deduced as;

$$
P R_{\varepsilon} S\left(S_{\varepsilon} P\right)=\sum\left[\left(P_{N}+M T S R_{N} \times P U_{r}\right)\left(\frac{2 M_{\operatorname{QX}} A U_{W K}}{A U_{W}}\right)\right]
$$

The sum price of maintenance for the whole system can be evaluated as

$$
\mathrm{T}^{P M}=\operatorname{PPS}\left(S_{\mathrm{v}} P\right)+P R_{\mathrm{v}} S\left(S_{\mathrm{v}} P\right) \ldots \ldots(E q \cdot B)
$$

From equation (8) therefore, it is possible find and evaluate bigger series.

After running the scripts in Simulink/Matlab, using its fitness function and pattern search algorithms, the following optimal patterns and graphs were generated (figure 5.1, 5.2, 5.3). 

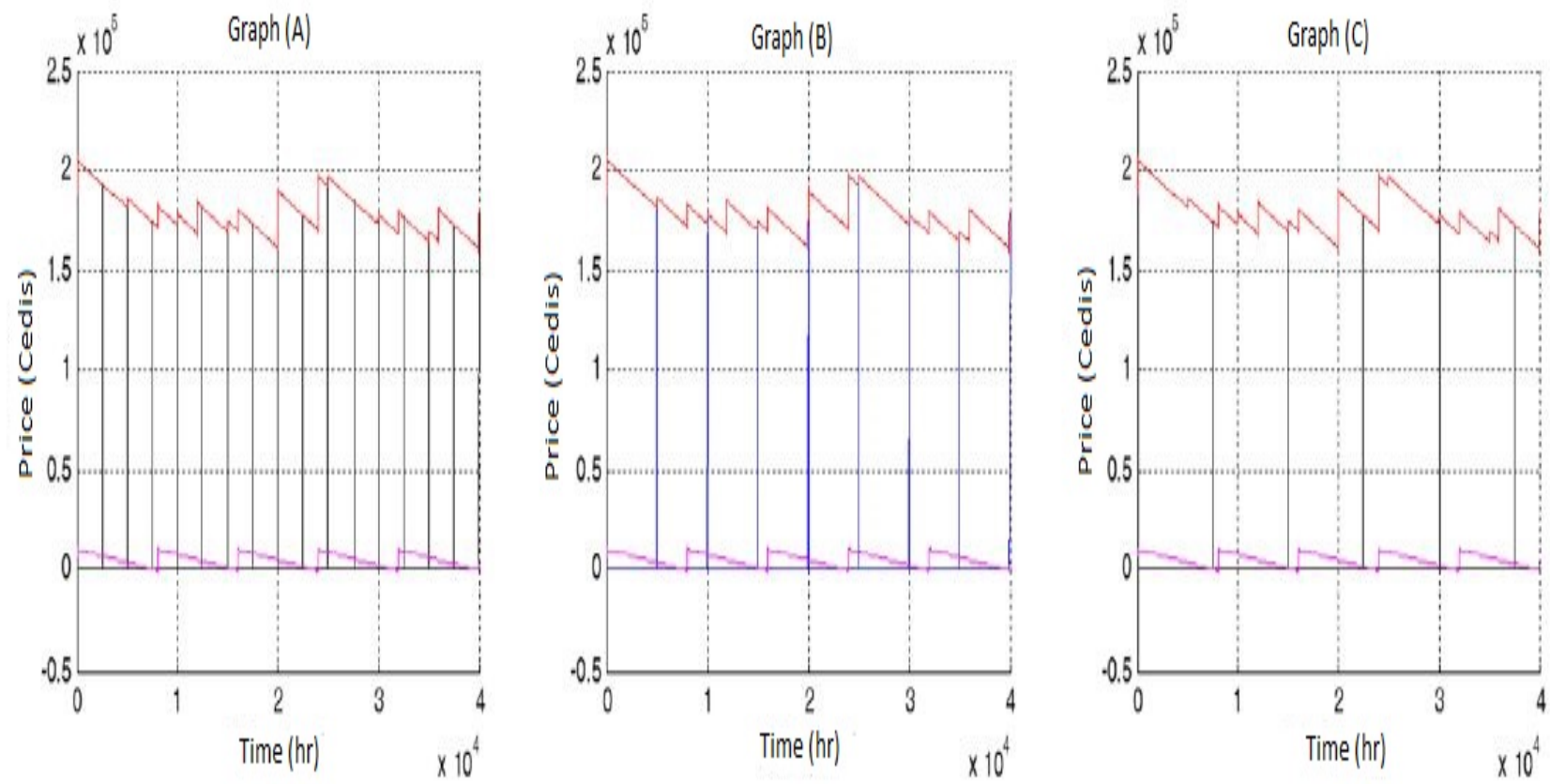

Figure 5.1. Signals Transmitted from various Blocks in the Simulation Model indicating patterns of maintenance prices and time of implementation

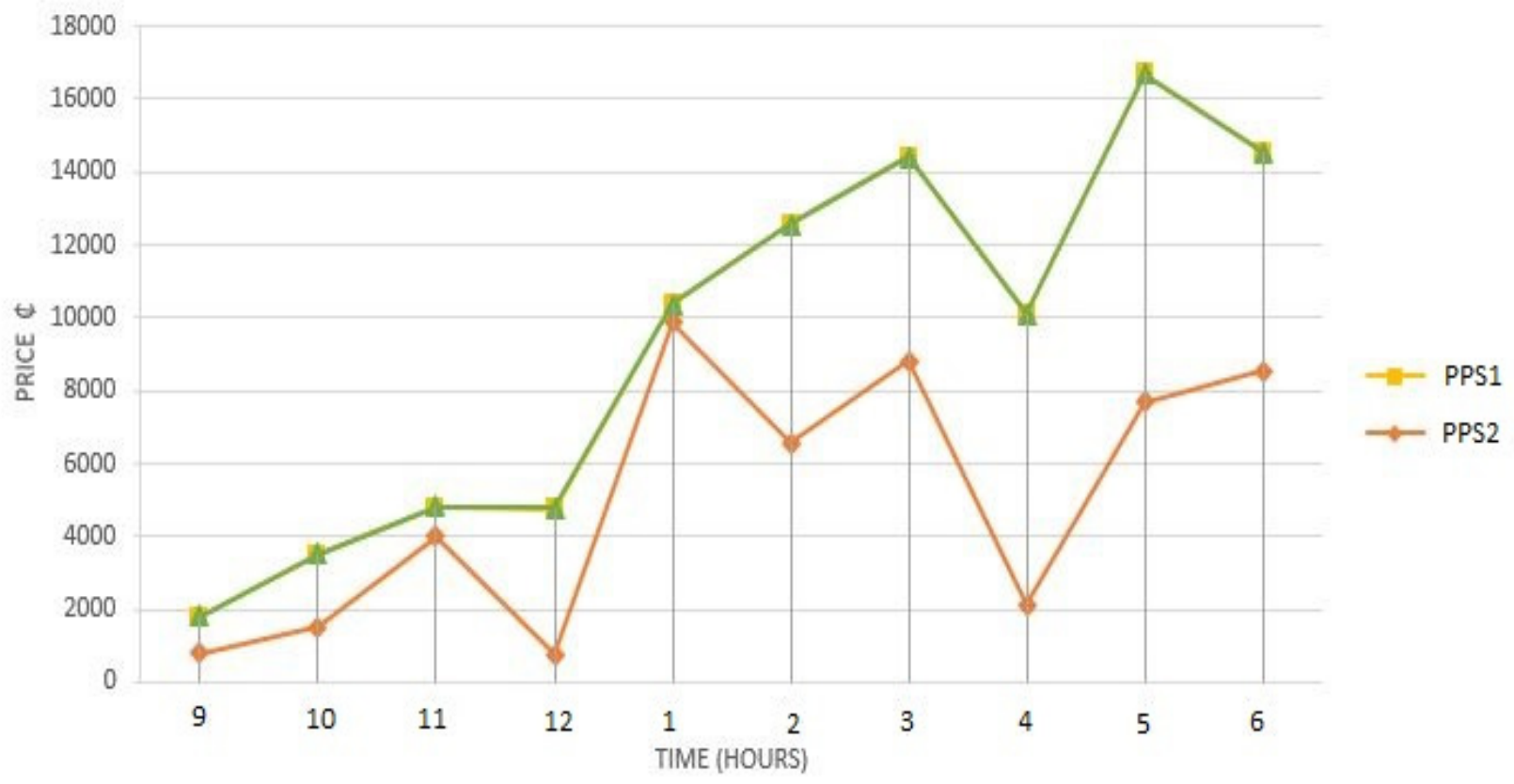

Figure 5.2. Structure of Preventive Service Prices and the Times of Maintenance Implementation 


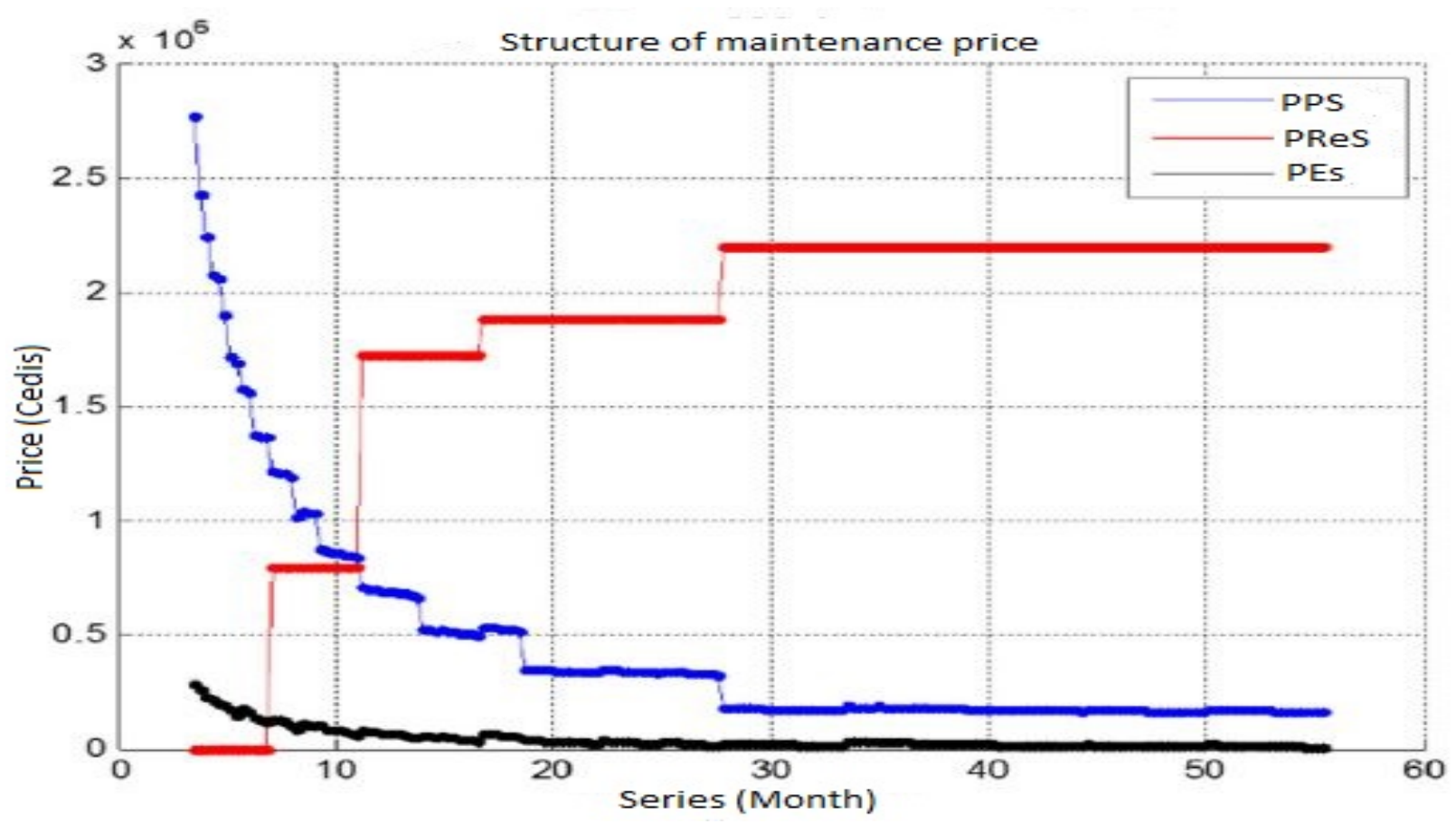

Figure 5.3. Structure of Maintenance Prices and the Times of Maintenance Implementation

\section{Discussion}

This section explains and relates the findings in a general discussion of the best maintenance practices in Ghana's food and beverage industry and the extent to which their operations are optimal in quality processes and output. Generally, it is explicit that Ghana's food and beverage industry is operating sub-optimally, given the main processes conducted on a normal day's production work; typically including spare part inventory control decision, maintenance management policies and practices and total quality assurance strategy implementation. This generally affects the effectiveness of their quest to compete with multinational firms. First of all, production floor well-structured to easy movement from one machine to another, and this would only be possible with a total change in machinery that can produce a better quality product in less time and with less cost. It is also observed that the majority of firms depend heavily on statistical models for planning and measuring production maintenance systems and output at the detriment of optimization models and software.

Moreover, planned preventive maintenance relative to corrective maintenance is generally lowly patronized except for specific equipment requirements. Spare inventories are procured to suit corrective maintenance purposes, with the absence of inventory control modes. This causes delays in the production system. Quality assurance practices in the industry is quite encouraging, with some level of sophistication and due diligence. The deficiency however, is the lack of consistency and standardization that characterize these practices. They tend to be done shoddily and sporadically. All the above results in huge margins of lost sales cost, poor quality products which cannot compete with multinational firms, reduced revenue and profitability, high total production cost and reduced international market shares. 
Unfortunately, since firms in the industry reports annual profits, they fail to appreciate their sub-optimal performance levels.

\section{Conclusion and Recommendations}

The food and beverage processing business in Ghana indicates a positive correlation with the main agricultural produce of the country and involves a series of activities including processing and preservation of meat, fish, fruit, vegetables, oils and fats; manufacture of dairy products; manufacture of grain mill products, starches and starch products and prepared animal feeds; and manufacture of other food products, such as bread, sugar, chocolate, pasta, coffee, nuts, spices, local wine and fruit drinks. Relative to the beverage production, food processing is carried out on a small scale. Major companies in the industry are GIHOC Distillery Limited, Healthi-Life Ghana Limited, Kasapreko Company Limited, Atona Foods and Parlays Ghana Limited.

Maintenance management and engineering system trends in the industry indicates an increasing use of contract maintenance by manufacturing companies across the globe in the last few years, especially among larger firms. In addition, a chunk of large enterprises and medium enterprises conduct most of their maintenance and repair work in-house, giving preference to contractors in Ghana. Planned preventive maintenance schemes are mainly deployed based on the equipment types available to the various firms. Gaining optimal values in production quality and maintenance acts was considered almost unattainable; which resulted in an unsatisfied demand in production due to the interruptions from the preventive maintenance interventions or workstation failures. Total Productive Maintenance (TPM) received a rather low application mainly by medium and large-scale enterprises, which was attributed to high cost of its implementation. A significant number of firms also combine different maintenance strategies, as needed, to suit their production and equipment schedules (Ribeiro et al., 2015).

The dominant spare part inventory management and quality control tools applied in the industry include Statistical Control Charts and Check Sheet in identifying products defects, as well as the Pareto Charts and Scatter diagram. The use of Fish Bone diagram for detecting quality problems was intermittent. In addition to the seven-main production quality control tools, some firms also use Pie charts, Line graph and System Process Audit. Quality Management Systems (QMS) is maintained in accordance with best industry practice, quality manual and documented standard operating procedures (SOP) but do not entirely conform to the requirements of ISO 9000: 2005 and ISO 9004:2009. Product testing is based on the Codex Alimentarius guidelines.

Major challenges bedeviling the food and beverage industry in Ghana include inefficient communication of quality policy to staff, lack of understanding the concept of TQM, inadequate resources to educate and train staffs, quality of raw materials from suppliers, poor machine maintenance culture, unwillingness of staff participation during production, high cost of ensuring production quality, management do not meet regularly in discussing quality issues, insufficiency of funds allocated to the maintenance function, reluctance of contractors to replace defective parts, and the limited employee participation because of 


\section{Macrothink}

level of education.

In conclusion, it is explicit that the near vibrant food and beverage industry of Ghana is confronted with some critical maintenance management and engineering system challenges which have stifled the optimal and superior performance of firms on both national and international markets. Maintenance management is done on intermittent basis without using advanced optimization models and technologies to ensure a best fit among production quality, spare part inventory control and maintenance acts.

It is indisputable per the discussions that have unfolded thus far in this research project that, production plant maintenance systems and practices are the most crucial factors that inhibit the optimal performance of firms and profitability in Ghana's food and beverage industry. Amidst the maintenance management challenges faced by the industry, firms have mainly implemented corrective maintenance practices as compared with preventive maintenance practices, and have also failed to deploy appropriate optimization strategies that consider critical maintenance management parameters in order to minimize total production cost whiles ensuring consistent production of quality products that meet the required conditions and demand rates of consumers. The project further re-emphasizes the need for strategic preventive maintenance acts to reduce cost and sustain competitive edge in the industry. The Matlab/Simulink software proved to be a multi-functional tool that enables the modeling, analysis and optimization of complex systems such as those of Ghana's food and beverage industry processes.

This study presents a better understanding of the various mechanisms of maintenance management of food and beverage industries with its focus on industries in Ghana. In view of that, more studies are also required in order to making full use of the excellent quality assurance practices as applied to other countries

\section{Funding}

The project received no funding from any source

\section{Conflict of interest statement}

The Authors declares that they have no conflict of interest.

\section{References}

Agyei-Boahene, A. (2010). FEASIBILITY OF JUST-IN-TIME (JIT) IN GHANA. Thesis submitted to the Department of Business Administration, Ashesi University College.

Al-Bawi, A. (2015). Spare parts management Potential in Production Sector. Sweden: Master Thesis Work. School of Innovation, Design and Engineering, Marlardalin University.

Ashayeri, J., Teelen, A., \& Selen, W. (1995). A production and maintenance planning model for the process industry. International Journal of Production Research.

Ashton, W., Richards, G., Galatsanou, E., \& Bollman, R. (2014). Food \& Beverage Processing Industry Growth Pathways to 2020. Rural Developement Institute. 


\section{Macrothink Institute ${ }^{T M}$}

Badiru, A.B. (2013). Handbook of Industrial and Systems Engineering (2nd ed.). Boca Raton: CRC Press, Taylor \& Francis Group. https://doi.org/10.1201/b15964

Baldwin, C. J. (2011). Sustainability in the Food Industry. USA: John Wiley \& Sons. https://doi.org/10.1002/9781118467589.ch9

Brown, A. C. (2014). Understanding Food: Principles and Preparation. UK: Cengage Learning.

Bruch, J., Bellgran, M., \& Bennett, D. (2014). Science, Technology and Innovation in the Age of Economic, Political and Security Issues". Collaborative Strategies for Successful Production Technology Development Projects. 23rd International Conference For the International Association of Management of Technology. At Washington DC, USA: ResearchGate.

Carlo, F., \& Arleo, M. A. (2017). Imperfect Maintenance Models, from Theory to Practice. https://doi.org/10.5772/intechopen.69286

Christiansen, B. (2018). Three of the Most Common Maintenance Challenges In the Food And Beverage Industry. Retrieved from Food Safety Tech: https://foodsafetytech.com/feature_article/three-of-the-most-common-maintenance-challenge s-in-the-food-and-beverage-industry/

Committee for Economic Development (CED). (2017). Economic Contribution of the Food and Beverage Industry. Arlington: The Conference Board: Trusted Insight for Business Worldwide.

Davis, B., Lockwood, A., Pantelidis, I., \& Alcott, P. (2013). Food and Beverage Management (5th ed.). USA: Routledge.

Dopson, L. R., \& Hayes, D. K. (2015). Study Guide to Accompany Food and Beverage Cost Control (6th ed.). New Jersey: John Wiley \& Sons.

Doumeizel, V. (2018). Current challenges in the food and beverage industry. Retrieved from Lloyd's

Register https://www.lr.org/en/insights/articles/current-challenges-in-the-food-industry/

EDU, S. A. (2013). Total Quality Management Practices Among Manufacturing Firms In Ghana (This Thesis Is Submitted To The University Of Ghana, Legon).

Enzing, C. (2009). Product Innovation in the Dutch Food and Beverage Industry: A Study on the Impact of the Innovation Process, Strategy and Network on the Product's Short-and Long-term Market Performance. Netherlands: Wageningen Academic Pub. https://doi.org/10.3920/978-90-8686-678-6

Food \& Drink Research Network. (2013). Ensuring Sustainable Employment and Competitiveness in the EU Food and Drink Industry: Meeting the Challenges of the Labour Market. UK: Improve Ltd in partnership with CERES:. 


\section{Macrothink Institute ${ }^{T M}$}

Food Engineering's annual report. (2018). 2018 Top 100 Food and Beverage Companies.

Retrieved from Food Engineering: https://www.foodengineeringmag.com/2018-top-100-food-beverage-companies

Gelagay, D. A., \& Balda, A. (2018). Inventory Management Practice in Micro and Small Enterprise: The Case of MSEs' Manufacturing Sub Sector Arsi Zone, Ethiopia. Industrial Engineering Letters, 7(7).

Hubbard, M. R. (2012). Statistical Quality Control for the Food Industry (3rd ed.). US: Springer Science \& Business Media.

Hurst, W. C., Tybor, P. T., Reynolds, A. E., \& Schchuler, G. A. (2010). Quality Control: A Model Program for the Food Industry. USA: University of Georgia Cooperative Extension Bulletin 997.

IMAP Consumer Staples Report. (2010). Food and Beverage Industry Global Report. www.imap.com.

Infor. (2012). How food \& beverage companies gain competitive advantage: The importance of implementing a least-cost formulation strategy. Retrieved from Infor Food \& Beverage, New York: www.infor.com.

International Finance Corporation (IFC). (2007). Environmental, Health, and Safety Guidelines: FOOD AND BEVERAGE PROCESSING. World Bank Group.

Jain, J. P. L. (2001). Quality Control and Total Quality Management. New Delhi: Tata McGraw-Hill Education.

Jankowicz, A. D. (2005). Business Research Projects (4th ed.). London: Thomson Learning.

Jiang, R., \& Murthy, D. N. P. (2008). Maintenance: Decision Models for Management. Beijing, China: Science press.

Kaplan, D. M. (2012). The Philosophy of Food. London: University of California Press.

Kersten, W. (2019). Supply Chain Performance Management: Current Approaches. Berlin: Erich Schmidt Verlag GmbH \& Co KG.

Laggoune, R., Mokhtar, W. A., \& Kheloufi, K. (2011). Preventive maintenance optimization based on both cost and availability measures, a case study. Conference: 41st ESReDA Seminar on Advances in Reliability-based Maintenance Policies. La Rochelle, France: Research Gate.

Ma, J., Cheng, L. \& Li, D. (2018). Road Maintenance Optimization Model Based on Dynamic Programming in Urban Traffic Network. Journal of Advanced Transportation. Article ID 4539324, 11 pages. https://doi.org/10.1155/2018/4539324

Makhado, M and Sukdeo, N. (2018). Advanced Manufacturing: The key to future competitiveness in the automotive industry. Proceedings of the International Conference on Industrial Engineering and Operations Management, July 26-27. Paris, France: IEOM 
Society International.

Maleti, D., Maletic, M., Al-Najjar, B. \& Gomiscek, B. (2012). The Role of Maintenance regarding improving product quality and Company's Profitability: A case Study. IFAC Workshop on Advanced Maintenance Engineering, Services and Technology. https://doi.org/10.3182/20121122-2-ES-4026.00040

Marchal, P. C., Ortega, J. G., \& García, J. G. (2018). Production Planning, Modeling and Control of Food Industry Processes. Switzerland: Springer.

MathWorks. (2005). SimEvents User's Guide. Retrieved from The MathWorks, Inc.

McGrath, M. (2018, June). World's Largest Food And Beverage Companies 2018: Anheuser-Busch, Nestle And Pepsi Top The List. Retrieved from Forbes: https://www.forbes.com/sites/maggiemcgrath/2018/06/06/worlds-largest-food-and-beveragecompanies-2018-anheuser-busch-nestle-and-pepsi-top-the-list/\#7cfa6cbe1b08

Morin, D. (2009). Fourier analysis. Havard Education: A potential book on Waves, designed for college.

Murthy, D. N. P., Atrens, A., \& Eccleston, J. A. (2001). Strategic Maiantenance Management. Journal of Quality in Maintenance Engineering, 8(4), 287-305. https://doi.org/10.1108/13552510210448504

Mwang'onda, E. S., Mwaseba, S. L., \& Juma, M. S. (2018). Industrialisation in Tanzania: The Fate of Manufacturing Sector Lies upon Policies Implementations. International Journal of Business and Economics Research, 7(3), 71-78. https://doi.org/10.11648/j.ijber.20180703.14

Nagib, A. M., Naufal, A. A., Ismail, A., Halim, N. H. A., \& Khusaini, N. S. (2016). The Role of Hybrid Make-to-Stock (MTS) - Make-to-Order (MTO) and Economic Order Quantity (EOQ) Inventory Control Models in Food and Beverage Processing Industry. International Engineering Research and Innovation Symposium (IRIS); IOP Conf. Series: Materials Science and Engineering. https://doi.org/10.1088/1757-899X/160/1/012003

Natural Capital Coalition. (2016). Natural Capital Protocol - Food and Beverage Sector Guide. Retrieved from Natural Capital Coalition: www.naturalcapitalcoalition.org/protocol

Nee, A. Y. C., Song, B., \& Ong, S. K. (2013). Re-engineering Manufacturing for Sustainability: Proceedings of the 20th CIRP International Conference on Life Cycle Engineering. Singapore: Springer Science \& Business Media. https://doi.org/10.1007/978-981-4451-48-2

Niir Project Consultancy Services (NPCS). (2012). Manufacture of Food \& Beverages (2nd ed.). Delhi: NIIR Project Consultancy Service.

Ofosu-Kwarteng, J. (2012). HealthCare Delivery and Customer Satisfaction in Ghana: A Case Study of Koforidua Regional Hospital. Kumasi: A Thesis Submitted to the Institute of Distance Learning, Kwame Nkrumah University of Science and Technology. Retrieved August 18, 2015, from ir.knust.edu.gh 


\section{Ml Macrothink}

Ohunakin, O. S, \& Leramo, O. (2012). Total Productive Maintenance Implementation in a Beverage Industry: A Case Study. Journal of Engineering and Applied Sciences, 7(2), 128-133. https://doi.org/10.3923/jeasci.2012.128.133

Opoku, Y. K. (2005). A short Guide to Research Writing in Social Sciences and Education. Accra: Ghana University Press.

Pennink, B., \& Jonker, J. (2010). The Essence of Research Methodology: A Concise Guide for Masters and PhD Students in Management Science. New York: Springer Science and Business Media.

Politeknik NSC Surabaya. (2007). Food and Beverage Operations: Prodution and Services. Retrieved from Politeknik NSC Surabaya E-Books Collection: https://nscpolteksby.ac.id/ebook/book/

Quaye, J. (2016). Evaluation of Quality Management System for An Alcoholic Beverage Industry (A Thesis Submitted To The Department Of Food Science And Technology, Kwame Nkrumah University Of Science And Technology).

Ribeiro, J., \& Sakey, S. M. (2014). Application of Modern Tools and Techniques for Equipment Maintenance in Ghanaian Industry. International Research Initiatives Conference. https://www.researchgate.net/publication/305471491.

Ribeiro, J. X. F., Sackey, S. M., \& Agyei-Agyemang, A. (2015). Status of Maintenance Engineering in Ghanaian Manufacturing Industry. African Journal of Applied Research $(A J A R), 1(1)$.

Rivera-Gómez, H., Montaño-Arango, O., Corona-Armenta, J. R., Garnica-González, J., Hernández-Gress, E. S., \& Barragán-Vite, I. (2018). Production and Maintenance Planning for a Deteriorating System with Operation-Dependent Defectives. Journal of Applied Scienes, 8(165). https://doi.org/10.3390/app8020165

Samanta, P. (2015). Introduction to inventory management. ResearchGate. Retrieved from https://www.researchgate.net/publication/317970709_INTRODUCTION_TO_INVENTORY _MANAGEMENT

Saunders, M., Lewis, P., \& Thornhill, A. (2009). Research Methods for Business Students (5th ed.). England: Pearson Education Limited.

Stillwell, J. (2013). Logic and Philosophy of Mathematics in the Nineteenth Century (In Ten, C.L. ed., Vol. VII). Routledge History of Philosophy.

Telang, A. D., \& Telang, A. (2010). Comprehensive Maintenance Management: Policies, strategies and Options. NewDehli: PHI Learning Private Limited.

Thi, P. K. N., Yeung, T., \& Castanier, B. (2010). Optimal maintenance and replacement decisions under technological change with consideration of spare parts inventories. International Symposium on Inventories. Hungary. 


\section{Macrothink}

Journal of Food Industry

ISSN 1948-545X 2020, Vol. 4, No. 1

Uzan, A., \& Ozdogan, A. (2012). Maintenance parameters based production policies optimization. Journal of Quality in Maintenance Engineering, 18(3), 295-310. https://doi.org/10.1108/13552511211265884

Vasili, M., Hong, T.S., Ismail, N., \& Vasili, M. (2011). Maintenance optimization models: a review and analysis. Proceedings of the 2011 International Conference on Industrial Engineering and Operations Management. Kuala Lumpur, Malaysia.

Wilson, J. (2010). Essentials of Business Research: A Guide to Doing Your Research Project. London: SAGE Publications Limited.

Yan, X. T., Jiang, C., \& Eynard, B. (2008). Advanced Design and Manufacture to Gain a Competitive Edge: New Manufacturing Techniques and their Role in Improving Enterprise Performance. London: Springer Science \& Business Media. https://doi.org/10.1007/978-1-84800-241-8

Zhong, R., Xu, X., \& Wang, L. (2017). Food supply chain management: systems, implementations and and future research. Industrial Management \& Data Systems. Emerald Insight, 117(9), 2085-2114. https://doi.org/10.1108/IMDS-09-2016-0391

\section{Copyright Disclaimer}

Copyright for this article is retained by the author(s), with first publication rights granted to the journal.

This is an open-access article distributed under the terms and conditions of the Creative Commons Attribution license (http://creativecommons.org/licenses/by/4.0/). 